\title{
ABCC6- a new player in cellular cholesterol and lipoprotein metabolism?
}

\author{
Patricia Kuzaj ${ }^{1}$, Joachim Kuhn ${ }^{1}$, Mareike Dabisch-Ruthe ${ }^{1}$, Isabel Faust ${ }^{1}$, Christian Götting ${ }^{2}$, Cornelius Knabbe ${ }^{1}$ \\ and Doris Hendig ${ }^{1 *}$
}

\begin{abstract}
Background: Dysregulations in cholesterol and lipid metabolism have been linked to human diseases like hypercholesterolemia, atherosclerosis or the metabolic syndrome. Many ABC transporters are involved in trafficking of metabolites derived from these pathways. Pseudoxanthoma elasticum (PXE), an autosomal-recessive disease caused by ABCC6 mutations, is characterized by atherogenesis and soft tissue calcification.

Methods: In this study we investigated the regulation of cholesterol biosynthesis in human dermal fibroblasts from PXE patients and healthy controls.

Results: Gene expression analysis of 84 targets indicated dysregulations in cholesterol metabolism in PXE fibroblasts. Transcript levels of ABCC6 were strongly increased in lipoprotein-deficient serum (LPDS) and under serum starvation in healthy controls. For the first time, increased HMG CoA reductase activities were found in PXE fibroblasts. We further observed strongly elevated transcript and protein levels for the proprotein convertase subtilisin/kexin type 9 (PCSK9), as well as a significant reduction in APOE mRNA expression in PXE.

Conclusion: Increased cholesterol biosynthesis, elevated PCSK9 levels and reduced APOE mRNA expression newly found in PXE fibroblasts could enforce atherogenesis and cardiovascular risk in PXE patients. Moreover, the increase in $A B C C 6$ expression accompanied by the induction of cholesterol biosynthesis supposes a functional role for ABCC6 in human lipoprotein and cholesterol homeostasis.
\end{abstract}

Keywords: Pseudoxanthoma elasticum, ABC transporter, ABCC6, Cholesterol biosynthesis, Atherosclerosis, HMG CoA reductase, SREBP2, PCSK9, LDLR, APOE

\section{Background}

ATP Binding Cassette $(\mathrm{ABC})$ proteins are important transporters for the delivery of hydrophobic compounds across cellular membranes [1]. To date, 48 human transporters have been described which can be classified into 7 subgroups [2]. Many ABC transporters are involved in trafficking of metabolites derived from lipid or cholesterol biosynthesis, e.g. sterols, bile acids, phospholipids, or sphingolipids [3]. Moreover, genetic mutations in $\mathrm{ABC}$ transporters have been linked to various human diseases [2,3], like Dubin-Johnson syndrome (ABCC2), Tangier disease (ABCA1), or Pseudoxanthoma elasticum (ABCC6).

\footnotetext{
* Correspondence: dhendig@hdz-nrw.de

${ }^{1}$ Herz- und Diabeteszentrum NRW, Institut für Laboratoriums- und Transfusionsmedizin, Universitätsklinik der Ruhr-Universität Bochum, Georgstraße 11, 32545 Bad Oeynhausen, Germany

Full list of author information is available at the end of the article
}

In contrast to other human transmembrane transporters, the characteristics and substrate spectra of which have already been explored, the function and physiological role of ABCC6 is still unclear [4]. Pseudoxanthoma elasticum (PXE) is an autosomal recessive disorder with an estimated prevalence of 1: 25.000- 50.000 [5]. To date, up to 350 causative genetic mutations have been found in ABCC6 [6].

PXE is characterized by soft tissue calcification affecting the skin, eyes and cardiovascular system [7]. Morphologically, mineralization occurs on elastic fibers which show increased degradation in PXE patients, in addition to abnormalities in collagen fibril assembly [8] and accumulation of proteoglycans [9]. Patients suffer from premature atherosclerosis, reduction in skin elasticity and visual detractions (angioid streaks, peau d'orange) [10]. Yellowish papules, marking flexural body sites, appear during the 
course of the disease [11]. Typically, xanthomas are characterized by cholesterolester accumulations in dermal foam cells [12], where cutaneous lesions of PXE derived from elastin calcification and fragmented fiber deposits [13]. The involvement of cholesterol or lipid depositions in PXE papule development is not clear. However, lipoproteins like the low density lipoprotein (LDL) have been examined for their capacity to bind to elastin, which increases under atherosclerotic conditions $[14,15]$.

ABCC6 is primarily expressed in the human liver and kidney, and to a lesser extent has been found in the skin, neural retina and vessel walls [16]. Moreover, Beck et al. detected ABCC6 mRNA in murine intestine, colon, brain, and eye [17]. Human dermal fibroblasts served as an appropriate model for soft tissue calcification in recent studies $[7,18,19]$. In addition to human skin fibroblasts, Abcc6-deficient (Abcc6 ${ }^{-} /^{-}$) mouse models were established for the examination of PXE pathogenesis [20,21].

Regarding the functionality and physiological role of ABCC6, essential knowledge is still missing. Several studies have been carried out to elucidate substrate specifications of ABCC6 in vitro, demonstrating the transport of glutathione conjugates [10]. However, in vitro experiments and investigations of Abcc6 in mice showed no transport activity for vitamin K3-glutathione conjugates or adenosine [22,23], rejecting previous ideas for its potential functionality $[24,25]$.

About twenty $\mathrm{ABC}$ transporters are involved in the carriage of compounds derived from lipid- or cholesterol metabolism and are important for reverse cholesterol transport (RCT) and phospholipid- and cholesterol efflux $[3,26]$. Voloshyna and Reiss summarized the functional role of ABCA1, ABCG1, ABCG4, ABCA5 and ABCA7 transporters in high-density lipoprotein (HDL)-mediated RCT, as well as ABCG5, ABCG8, ABCB4 and ABCB11 for biliary lipid secretion within the scope of atheroprotection [26]. Additionally, members of the ABCC subgroup, like $\mathrm{ABCC} 1, \mathrm{ABCC} 2$ and $\mathrm{ABCC} 3$, are further needed for bile acid and bilirubin efflux [3]. Studies have described genetic mutations in ABCC6 to be associated with variations in quantitative plasma lipoproteins [27], low HDL-C and/or coronary heart disease (CHD) risk [28]. Alterations in lipoprotein composition with lowered plasma HDL cholesterol levels and hypertriglyceridemia were found in plasma samples of PXE patients [29]. Furthermore, experiments in Abcc6 ${ }^{-}{ }^{-}$mice showed a $25 \%$ reduction in plasma HDL cholesterol [20], confirming the potential role of ABCC6 in lipid homeostasis as described before [30]. Recently, Guo et al. demonstrated that atorvastatin counteracts soft tissue mineralization in Abcc6-deficient mice [31]. Statins are widely used to inhibit HMG CoA reductase activity, the rate-limiting step in cholesterol biosynthesis, to reduce plasma low-density lipoprotein cholesterol (LDL-C) levels and CHD risk [32]. Oxidized-
LDL fractions have been described as the major stimuli for plaque formation and atherosclerotic development [33], as well as for angiogenesis [34]. In addition to statin treatments, inhibition of the proprotein convertase subtilisin/kexin type 9 (PCSK9) is under recent examination to lower circulating LDL levels, while PCSK9 negatively regulates the low-density lipoprotein receptor (LDLR) by promoting its lysosomal degradation [35].

Here, we describe for the first time HMG CoA reductase activity measurements in human dermal fibroblasts derived from PXE patients and healthy controls, as well as for ABCC6-silenced cells. Moreover, we carried out gene expression profiling of 84 targets involved in cholesterol biosynthesis and lipoprotein signaling in human dermal fibroblasts cultivated without fetal calf serum (-FCS) for $24 \mathrm{~h}$. Significant alterations were further investigated under different cell culture conditions, using $10 \%$ fetal calf serum, $10 \%$ lipoprotein-deficient serum (LPDS) and serum starvation (-FCS) to stimulate HMG CoA reductase activity. Our results indicate that functional loss or dysfunction of ABCC6 in PXE dermal fibroblasts is significantly associated with alterations in cellular cholesterol metabolism and lipoprotein assembly.

\section{Materials and methods \\ Cell culture}

Primary human dermal fibroblasts from four PXE patients were isolated and specified as described previously [18]. None of the investigated patients was reported to suffer from dyslipidemia. Dermal fibroblasts from four apparently healthy controls were purchased from Promocell (Heidelberg, Germany), Genlantis (San Diego, USA), Cambrex (Walkersville, USA) and Coriell Institute for Medical Research (Camden, USA). All cells were isolated and characterized by standard methods. The study was approved by the ethics commission of the Ruhr University of Bochum Faculty of Medicine, located in Bad Oeynhausen. All patients provided their written informed consent to participate in the study. Characterization of human dermal fibroblasts is given in Additional file 1: Table S1. Cultivation was performed in Dulbecco's modified essential medium (DMEM, Gibco) containing 10\% fetal calf serum (PAN Biotech, Aidenbach, Germany), $1 \%$ L-glutamine $(200 \mathrm{mM})$ and $1 \%$ antibiotic/antimycotic solution without phenol red, whereupon cells were subcultured every 4-5 days (1:3) as they reached confluence.

For experiments cells were grown for $24 \mathrm{~h}$ in $10 \%$ FCS (177 cells $/ \mathrm{mm}^{2}$, BD Falcon), washed twice with phosphatebuffered saline (PBS; Gibco), and replaced with either $10 \%$ fetal calf serum (FCS), lipoprotein-deficient FCS (LPDS) [36], or without serum for additional $24 \mathrm{~h}$. Cells reached approx. $70-80 \%$ of confluence after stated time of growth. Biological samples were prepared in triplicates using passages 7-10. Cells harvested for RNA 
isolation and protein lysis were treated as described before $[37,38]$.

\section{Gene silencing of ABCC6 using small-interfering RNA}

Lipofectamine 2000 reagent (Invitrogen- Life technologies, Darmstadt, Germany) was used to deliver ABCC6-specific small-interfering RNA (siRNA-ID 106395) and FAM labeled scrambled control siRNA oligonucleotides (AmbionLife technologies, Darmstadt, Germany) to dermal fibroblasts of healthy controls during reverse transfection, in a total siRNA-concentration of $40 \mathrm{nM}$. No antibiotic/ antimycotic solution was used during the first $12 \mathrm{~h}$. Cell culture medium was replaced with fresh media $12 \mathrm{~h}$ post-transfection, whereupon transfection efficiencies were examined by fluorescence microscopy of FAM labeled controls. Cells were cultivated for additional $48 \mathrm{~h}$ in $10 \%$ FCS, followed by $24 \mathrm{~h}$ cultivation in either $10 \%$ FCS, $10 \%$ lipoprotein deficient serum (LPDS), or without FCS.

\section{$\mathrm{RT}^{2}$ Profiler PCR Array}

A broad gene expression analysis was performed covering 84 target genes involved in lipoprotein signaling and cholesterol metabolism by using $\mathrm{RT}^{2}$ Profiler PCR Array (Qiagen, Hilden, Germany, PAHS 080ZA). PCR array was performed with cells cultivated for $24 \mathrm{~h}$ without FCS, and 3 biological replicates were pooled for array analysis. RNA was isolated as described before [37], whereupon $400 \mathrm{ng}$ were used for cDNA-synthesis ( $\mathrm{RT}^{2}$ First Strand Kit; Qiagen, Hilden, Germany). Real-Time PCR was performed using LightCycler 480 (Roche, Penzberg, Germany) and $\mathrm{RT}^{2}$ SYBR Green qPCR reaction mixture (Qiagen, Hilden, Germany). Reaction mixture and PCR cycles were performed according to the manufacturer's instructions. Relative gene expression was analyzed using $\Delta \Delta \mathrm{C}_{\mathrm{t}}$ based fold-change calculations.

\section{Real time quantitative PCR analysis}

Real-Time quantitative PCR (qPCR) was performed using LightCycler 480 and LightCycler 480 SYBR Green I Master reaction mixture (Roche, Penzberg, Germany). RNA was isolated as described above, whereupon $2 \mu \mathrm{g}$ were used for cDNA-synthesis (SuperScript II Reverse Transcriptase, Invitrogen- Life technologies, Darmstadt, Germany).

Primer sequences are listed in Additional file 2: Table S2. cDNA was used at 1:10 dilution; targets with low gene expression were measured using 1:5 diluted cDNA. A cutoff for no detectable mRNA expression was set to a $C_{t}$ level of 35 for further relative gene expression analysis (carried out as described before [18]), with ACTB, GAPDH and $\beta 2 \mathrm{M}$ as reference genes, according to MIQE guidelines [39].

\section{Protein extraction and quantification}

Preparation of protein lysates was performed as described before [38]. Total protein content of cell lysates was estimated using bicinchoninic acid assay (BCA Kit, Sigma Aldrich, Taufkirchen, Germany).

\section{HMG CoA enzyme activity assay}

Enzyme activity assay for HMG CoA reductase was determined for each biological replicate. Procedures were carried out as described before [38], using $100 \mu \mathrm{M}$ of HMG CoA as initial substrate. Detection of MVL levels was monitored by an ultra-performance liquid chromatography (UPLC) system (Waters Acquity UPLC) using a $2.1 \mathrm{~mm} \times 150 \mathrm{~mm}$ HSS PFP UPLC/MS cartridge (Waters, $1.8 \mu \mathrm{m}$ ACQUITY UPLC HSS PFP Column) conducted at $45^{\circ} \mathrm{C}$, which was directly coupled to a Quattro LC tandem mass spectrometer equipped with $\mathrm{Z}$ Spray ion source (Waters Xevo ${ }^{\text {Tx }}$ TQ-S).

\section{Quantitation of cellular proprotein convertase subtilisin/ kexin type 9 (PCSK9)}

Human PCSK9 in cell lysates of dermal fibroblasts was measured using Human PCSK9 ELISA Kit (Cell Biolabs, Inc., San Diego, USA) according to the manufacturer's instructions. Protein lysates were obtained as described above. $5 \mu \mathrm{g}$ of total cellular protein were used for enzyme immunoassay, measuring fibroblast samples in duplicates.

\section{Apolipoprotein E (APOE) genotyping}

Genotyping of apolipoprotein $\mathrm{E}$ was performed according to the previously published method by Wenham et al. [40]. Isolated DNA of patients and controls was screened for apolipoprotein E sequence variations at position c.334 $(\mathrm{T}>\mathrm{C})$ and c.472 $(\mathrm{C}>\mathrm{T})$ by PCR on a LightCycler 480 (Roche, Applied Science). PCR was performed with fluorescence resonance energy transfer (FRET)-probes (fluorescein, LCRed 640). APOE genotypes were identified using melting curve analysis. Specific melting peak detection allows the characterization of homozygous or heterozygous sequence types, regarding melting temperatures and number of peaks.

\section{Statistical analysis}

Experimental data are indicated as means \pm S.E. Graphic data processing and statistics were performed with GraphPad Prism 5 (GraphPad Software, Inc., La Jolla, USA) using Mann-Whitney $U$ Test (significance level $\mathrm{p}<0.05)$.

\section{Results \\ $\mathrm{RT}^{2}$ profiler PCR array}

Analysis of 84 genes involved in cholesterol metabolism and lipoprotein signaling revealed altered mRNA levels between PXE fibroblasts and healthy controls grown in 
serum-free media for $24 \mathrm{~h}$. Table 1 summarizes gene expressions regulated $>2$-fold, or $<0.5$-fold between PXE and control cells, as well as for siRNA-transfected cells. All results of PCR profiler array are provided in Additional file 3: Table S3. Fold-changes were characterized by comments (OKAY/A/B/C) based on the gene's average threshold cycle as described in Table 1. Relative mRNA expression of proprotein convertase subtilisin/ kexin type 9 (PCSK9) exhibited a 46-fold increase in PXE fibroblasts $(\mathrm{p}<0.04)$ compared to healthy controls, whereas no differences were found between siRNAtransfected cells. Furthermore, 2.4-fold elevation of transmembrane 7 superfamily member 2 (TM7SF2) mRNA level in PXE cells revealed statistical significance $(p<0.04)$, which was also confirmed by trend with siRNA transfection (siABCC6/ siNK ratio: 2.1-fold). All other regulations were elevated or decreased by trend and no statistical significance was found due to insufficient sample size or low expression levels (see also comment description, Table 1. Array analysis showed distinct differences in apolipoprotein mRNA expressions between patient and control samples. A 124.6-fold increase was found for apolipoprotein L1 (APOL1) expression in PXE fibroblasts compared to control cells. Although, transcript levels of apolipoprotein D (APOD) were 2.3-fold higher in PXE fibroblasts. Expressions of apolipoprotein E (APOE), F (APOF) and L5 (APOL5) were decreased in PXE samples (patient/control ratio: 0.07; patient/control ratio: 0.5 ; patient/control ratio: 0.2 , respectively), whereas a reduction in APOE expression was also confirmed by siRNA treatments (siABCC6/ siNK ratio: 0.5).

Table $1 \mathbf{R T}^{2}$ profiler PCR array, lipoprotein signaling and cholesterol metabolism

\begin{tabular}{|c|c|c|c|c|c|c|c|}
\hline \multirow[b]{2}{*}{ Gene } & \multirow[b]{2}{*}{ Description } & \multicolumn{3}{|c|}{ PXE/control } & \multicolumn{3}{|c|}{ siABCC6/siNK } \\
\hline & & $\begin{array}{c}\text { Fold } \\
\text { change }^{a}\end{array}$ & $\begin{array}{l}\mathrm{p} \text {-value } \\
(t \text {-test })^{\mathrm{b}}\end{array}$ & Comments $^{c}$ & $\begin{array}{c}\text { Fold } \\
\text { change }^{a}\end{array}$ & $\begin{array}{l}\text { p-value } \\
(t \text {-test })^{b}\end{array}$ & Comments $^{c}$ \\
\hline$\overline{A B C G 1}$ & ATP-binding cassette, sub-family G member 1 & 1.89 & 0.334 & B & 0.34 & 0.421 & B \\
\hline ANGPTL3 & Angiopoietin-like 3 & 3.09 & 0.249 & A & 1.24 & 0.294 & A \\
\hline APOD & Apolipoprotein D & 2.29 & 0.328 & OKAY & 0.92 & 0.796 & OKAY \\
\hline APOE & Apolipoprotein E & 0.07 & 0.313 & A & 0.51 & 0.847 & A \\
\hline APOF & Apolipoprotein F & 0.47 & 0.353 & B & 1.90 & 0.343 & B \\
\hline APOL1 & Apolipoprotein L, 1 & 124.57 & 0.095 & A & 1.03 & 0.919 & B \\
\hline APOL5 & Apolipoprotein L, 5 & 0.23 & 0.123 & B & 1.05 & 0.660 & C \\
\hline CEL & Carboxyl ester lipase (bile salt-stimulated lipase) & 2.68 & 0.341 & A & 2.84 & 0.331 & A \\
\hline CXCL16 & Chemokine (C-X-C motif) ligand 16 & 0.49 & 0.192 & B & 1.09 & 0.869 & OKAY \\
\hline CYP39A1 & Cytochrome P450, family 39, subfamily A, polypeptide 1 & 3.64 & 0.068 & A & 1.05 & 0.809 & B \\
\hline CYP46A1 & Cytochrome P450, family 46, subfamily A, polypeptide 1 & 0.57 & 0.250 & B & 0.47 & 0.192 & B \\
\hline HDLBP & High density lipoprotein binding protein & 6.99 & 0.751 & OKAY & 0.99 & 0.989 & OKAY \\
\hline LRP1B & Low density lipoprotein receptor-related protein 1B & 5.18 & 0.092 & B & 0.43 & 0.265 & B \\
\hline NPC1L1 & NPC1 (Niemann-Pick disease, type C1, gene) like 1 & 0.36 & 0.161 & B & 0.89 & 0.562 & B \\
\hline OLR1 & Oxidized low density lipoprotein (lectin-like) receptor 1 & 0.29 & 0.120 & B & 2.34 & 0.581 & B \\
\hline PCSK9 & Proprotein convertase subtilisin/kexin type 9 & 46.23 & 0.033 & A & 1.18 & 0.820 & B \\
\hline SORL1 & Sortilin-related receptor, L(DLR class) A repeats containing & 1.77 & 0.112 & B & 2.18 & 0.390 & B \\
\hline TM7SF2 & Transmembrane 7 superfamily member 2 & 2.40 & 0.034 & OKAY & 2.05 & 0.079 & OKAY \\
\hline TRERF1 & Transcriptional regulating factor 1 & 4.93 & 0.222 & OKAY & 3.98 & 0.209 & OKAY \\
\hline
\end{tabular}

Regulated gene expression of human dermal fibroblasts of PXE patients and healthy controls (PXE/controls) and siRNA transfected cells (siABCC6/siNK) cultivated without FCS for $24 \mathrm{~h}$.

${ }^{a}$ fold-Change $\left(2 \wedge\left(-\Delta \Delta C_{t}\right)\right)$ is the normalized gene expression $\left(2 \wedge\left(-\Delta C_{t}\right)\right)$ in the test sample divided the normalized gene expression $\left(2 \wedge\left(-\Delta C_{t}\right)\right)$ in the control sample.

${ }^{b} p$-values are calculated based on a Student's $t$-test of the replicate $2 \wedge\left(-\Delta C_{t}\right)$ values for each gene in the control group and treatment groups, and $p$ values less than 0.05 are printed in bold.

comments

OKAY: This gene's average threshold cycle is below 30 in the control and test samples.

A: This gene's average threshold cycle is relatively high $(>30)$ in either the control or the test sample, and is reasonably low in the other sample $(<30)$.

$\mathrm{B}$ : This gene's average threshold cycle is relatively high $(>30)$, meaning that its relative expression level is low, in both control and test samples, and the $\mathrm{p}$-value for the fold-change is either unavailable or relatively high $(p>0.05)$.

C: This gene's average threshold cycle is either not determined or greater than the defined cut-off value (default 35), in both samples meaning that its expression was undetected, making this fold-change result erroneous and un-interpretable. 
ABCC6 gene expression in human dermal fibroblasts is highly increased under serum starvation

As shown in Figure 1a, no mRNA expression of ABCC6 was quantifiable in PXE fibroblasts. Relative gene expression of ABCC6 was significantly increased in control fibroblasts under lipoprotein-deficient conditions (1.9-fold) and serum starvation (7.1-fold). A similar expression pattern was observed in siRNA-transfected control cells (Figure 1b; $+10 \%$ LPDS: 1.6-fold; -FCS: 5.0-fold), while transcript levels of ABCC6 were downregulated by $64.5 \%$ (10\% FCS), 65\% (10\% LDPS) and $75.2 \%$ (-FCS) in siABCC6-transfected cells compared to $\operatorname{siNK}(\mathrm{p}<0.0001)$.

\section{Elevated HMG CoA reductase (HMGCR) enzyme activity in PXE fibroblasts}

Determination of HMGCR gene expression by qPCR revealed a significant increase in accordance with modified cell culture conditions (Figure 2a) in PXE and control fibroblasts compared to fibroblasts cultivated in 10\% FCS (+10\% LDPS: control, 2.6-fold; PXE, 2.9-fold; -FCS: control, 1.4-fold; PXE, 2.1-fold). Delipidation of fetal calf serum (LPDS) reduced free cholesterol by about $85 \%$ and LDL levels by about $96 \%$, whereas triglyceride levels remained unchanged (data not shown).

Measurements of HMG CoA reductase activity showed significantly elevated enzyme activities in PXE fibroblasts compared to control cells for each cell culture setting (Figure 2c; +10\% FCS: 1.6 -fold; +10\% LDPS: 1.5 fold; -FCS: 2.1-fold). Activity was increased in LDPS or serum-free media in PXE fibroblasts compared to $10 \%$ FCS (+10\% LDPS: PXE, 6.4-fold; -FCS: PXE, 2.1-fold) and a 7.1-fold induction was also observed in control fibroblasts grown in LPDS. However, overall enzyme activity was lower in siRNA-transfected samples compared to PXE and control fibroblasts (Figure 2b). Here, increasing enzyme activities were also detected in LPDS (siNK, 11.6-fold; siABCC6, 5.7-fold) and serum-free treatment of siRNA control (4.0-fold) compared to $10 \%$ FCS. However, no alterations were found between siNK and siABCC6 samples, except for cells cultivated in 10\% FCS (siABCC6/ siNK ratio: 2.0 ).

\section{Lipoprotein deficiency and serum starvation induce cholesterol biosynthetic gene expression in human dermal fibroblasts}

In addition to HMGCR, marking the rate-limiting step in cholesterol biosynthesis, gene expression of farnesyl diphosphate synthase (FDPS), geranylgeranyl diphosphate synthase 1 (GGPS1), squalene synthase (FDFT1), lanosterol synthase (LSS), transmembrane 7 superfamily member 2 (TM7SF2) and 7-dehydrocholesterol reductase (DHCR7) were analyzed (Figures 3 and 4).

Under serum-free conditions, PXE fibroblasts exhibited a significant increase in all targets mentioned above (except GGPS1) compared to healthy controls, which were mostly confirmed by ABCC6 knockdown (Figures 3 and 4; FDPS: PXE, 2.0-fold; siABCC6, 1.4-fold; FDFT1: PXE, 1.8-fold; siABCC6: 1.5-fold; LSS: PXE, 1.5-fold; siABCC6: 1.5-fold; TM7SF2: PXE, 2.1-fold; siABCC6, 1.8-fold; DHCR7: PXE, 1.6-fold; siABCC6, 1.4-fold; p values are given in Figures 3 and 4).

Using LPDS, transcript levels of the analyzed targets in PXE cells were slightly elevated or unchanged relative to healthy controls (Figures 3 and 4; FDPS: PXE, 1.4-fold; FDFT1: PXE, 1.1-fold; LSS: PXE, 1.2-fold; TM7SF2: PXE, 1.3-fold; DHCR7: PXE, 1.1-fold; $\mathrm{p}$-values are given in Figure 3.18, 3.19). ABCC6-silenced fibroblasts showed even slightly increased or unaltered mRNA levels under
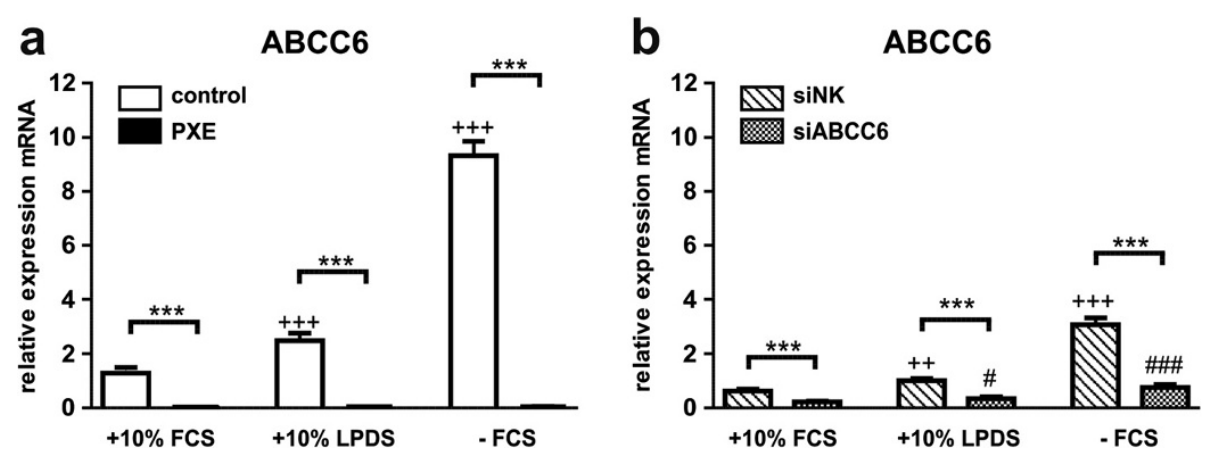

Figure 1 Gene expression analysis of ABCC6. (a) Quantification of ABCC6 mRNA expression in human dermal fibroblasts from healthy controls ( $n=4$; white) and PXE patients ( $n=4$; black) grown for $24 \mathrm{~h}$ under different cell culture conditions (+10\% FCS, +10\% LPDS, -FCS). (b) Effect of siRNA-mediated knockdown on ABCC6 gene expression: fibroblasts transfected with a scramble siRNA-negative control (siNK, $n=4$; white-striped); ABCC6-specific siRNA-treated cells (siABCC6, $n=4$; black-shaded) grown for 24 h under different cell culture conditions (+10\% FCS, +10\% LPDS, -FCS). Expression levels are normalized to reference gene expressions (ACTB, GAPDH, $\beta 2 \mathrm{M}$ ). Data are presented in arbitrary units as means with corresponding standard error. Control: PXE ratio/siABCC6: siNK ratio: ${ }^{* *} \mathrm{p}<0.0001$; Control 10\% FCS: 10\% LPDS, -FCS ratio/siNK 10\% FCS: $10 \%$ LPDS, -FCS ratio: $+++p<0.0001 ;++p<0.003$; PXE 10\% FCS: 10\% LPDS, -FCS ratio/siABCC6 10\% FCS: 10\% LPDS, -FCS ratio: \#\#\#p < 0.0001; \#p < 0.04. 

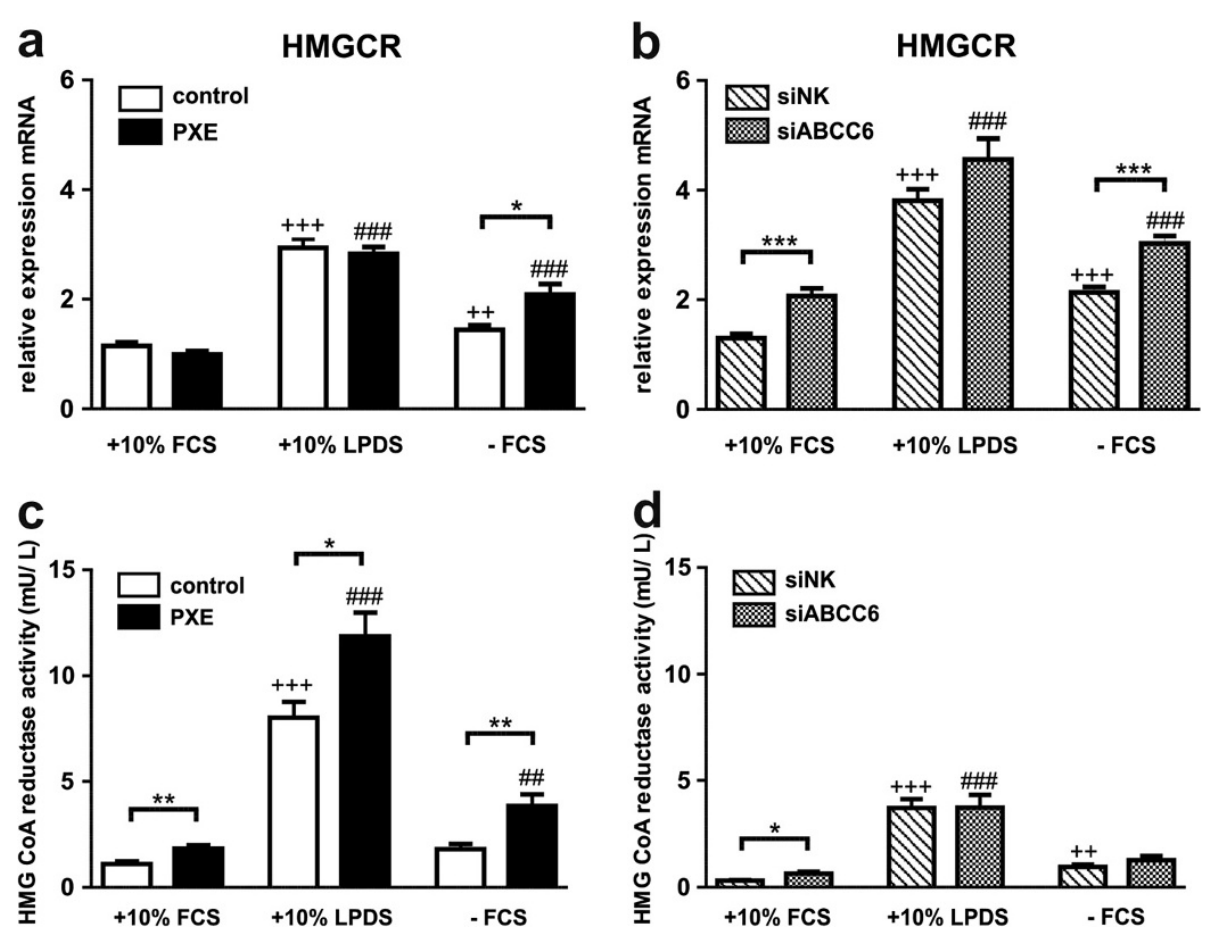

Figure 2 Gene expression and enzyme activity analysis of HMG CoA reductase (HMGCR). (a) Quantification of HMGCR mRNA expression in human dermal fibroblasts from healthy controls $(n=4$; white) and PXE patients ( $n=4$; black) grown for $24 \mathrm{~h}$ under different cell culture conditions ( $+10 \%$ FCS, $+10 \%$ LPDS, $-F C S)$. (b) Effect of siRNA-mediated knockdown on ABCC6 gene expression: fibroblasts transfected with a scramble siRNA-negative control (siNK, $n=4$; white-striped); ABCC6-specific siRNA-treated cells (siABCC6, $n=4$; black-shaded) grown for $24 \mathrm{~h}$ under different cell culture conditions (+10\% FCS, $+10 \%$ LPDS, $-F C S)$. Expression levels are normalized to reference gene expressions (ACTB, GAPDH, ß2M). Data are presented in arbitrary units as means with corresponding standard error. Control: PXE ratio/siABCC6: siNK ratio: ${ }^{* * *} \mathrm{p}<0.0001 ;{ }^{*} \mathrm{p}<0.03$; Control 10\% FCS: 10\% LPDS, -FCS ratio/siNK 10\% FCS: 10\% LPDS, -FCS ratio: +++p <0.0001; ++p < 0.004; PXE 10\% FCS: 10\% LPDS, -FCS ratio/siABCC6 10\% FCS: 10\% LPDS, -FCS ratio: \#\#\#p < 0.0001 (c, d) Enzyme activity of HMG CoA reductase in fibroblasts of healthy controls, PXE patients (c) and siRNA- treated cells (d) measured by UPLC-MS/MS. Data are presented in arbitrary units as means with corresponding standard error. Control: PXE ratio/siABCC6: siNK ratio: ${ }^{*} p<0.003$; ${ }^{*} p<0.03$; Control 10\% FCS: 10\% LPDS, -FCS ratio/siNK 10\% FCS: 10\% LPDS, - FCS ratio: $+++p<0.0001$; $++p<0.002$; PXE 10\% FCS: 10\% LPDS, -FCS ratio/siABCC6 10\% FCS: 10\% LPDS, -FCS ratio: \#\#\#p <0.0001; \#\#p <0.009.

LPDS cultivation in comparison to siRNA controls (Figures 3 and 4).

Cell cultivation in $10 \%$ LPDS increased mRNA expression of all targets in PXE and control fibroblasts, as well as in siRNA treated cells in comparison to $10 \%$ FCS (Figures 3 and 4). Only a slight increase under serum-free culture conditions was found for gene expression analysis of GGPS1 in patients and controls (Figure 3c, d).

Additionally, transcript levels (except FDPS mRNA expression of control fibroblasts) increased significantly under serum deprivation (-FCS) compared to standard cultivation in $10 \%$ FCS.

Sterol regulatory element-binding protein 2 (SREBP2) and sterol regulatory element-binding factor 1 (SREBF1) increased in response to lipoprotein reduction and serum withdrawal

Sterol regulatory element-binding protein 2 (SREBP2) increases LDLR and PCSK9 gene expression, as a sterol sensitive regulator in cholesterol homeostasis [35]. Induction of SREBP2 and SREBF1 mRNA expression was observed in $10 \%$ LPDS and serum-free media compared to $10 \%$ FCS (Figure 5a-d). No significant changes of SREBP2 transcript levels were detected between PXE and control cells (Figure 5a). However, SREBF1 mRNA was significantly elevated in PXE fibroblasts under serum starvation (patient/control ratio: 1.5). Altered gene and protein expression of proprotein
convertase subtilisin/kexin type 9 (PCSK9) and low
density lipoprotein receptor (LDLR) in PXE fibroblasts Gene expression analysis of PCSK9 by $\mathrm{RT}^{2}$ Profiler PCR Array revealed a 46-fold increase in PXE fibroblasts compared to healthy controls grown under serum-free conditions (see section $\mathrm{RT}^{2}$ Profiler PCR Array).

Verification by further qPCR showed significantly elevated mRNA expression in PXE fibroblasts for all cell culture settings in comparison to controls (Figure $6 \mathrm{a}:+10 \%$ FCS: 2.0-fold; +10\% LDPS: 2.2-fold; -FCS: 4.1-fold). 

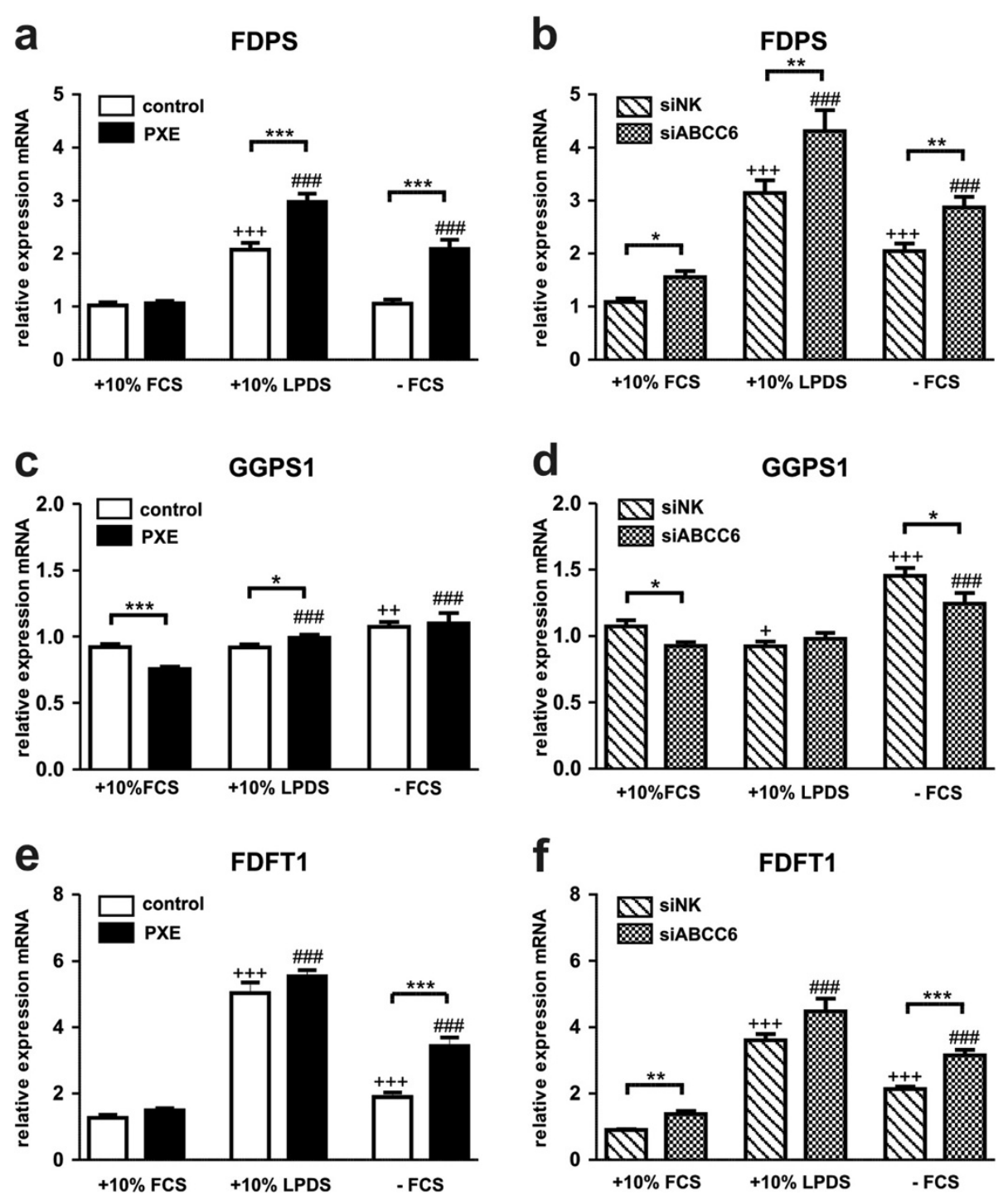

Figure 3 Gene expression analysis of cholesterol biosynthesis I: FDPS, GGPS1 and FDFT1. Quantification of (a, b) Farnesyl diphosphate synthase (FDPS), (c, d) Geranylgeranyl diphosphate synthase (GGPS1) and (e, f) Squalene synthase (FDFT1) mRNA expression in human dermal fibroblasts from healthy controls $(n=4$; white), PXE patients $(n=4$; black), scramble siRNA-negative control (siNK, $n=4$; white-striped) and ABCC6-specific siRNA-treated cells (siABCC6, $n=4$; black-shaded) grown for $24 \mathrm{~h}$ under different cell culture conditions $(+10 \% \mathrm{FCS},+10 \% \mathrm{LPDS},-\mathrm{FCS})$. Expression levels are normalized to reference gene expressions (ACTB, GAPDH, $\beta 2 \mathrm{M}$ ). Data are presented in arbitrary units as means with corresponding standard error. Control: PXE ratio/siABCC6: siNK ratio: ${ }^{* * *} \mathrm{p}<0.0003 ;{ }^{* *} \mathrm{p}<0.003 ;{ }^{*} \mathrm{p}<0.04$; Control 10\% FCS: $10 \%$ LPDS, - FCS ratio/siNK $10 \%$ FCS: $10 \%$ LPDS, -FCS ratio: $+++p<0.0006 ;++p<0.003 ;+p<0.05$; PXE 10\% FCS: 10\% LPDS, -FCS ratio/siABCC6 10\% FCS: 10\% LPDS, -FCS ratio: \#\#\#p <0.0007.

Moreover, PCSK9 expression was highly induced under lipoprotein-deficient and serum-free conditions in controls and PXE fibroblasts compared to $10 \%$ FCS $(10 \%$ LPDS: control, 5.1-fold; PXE, 5.5-fold; -FCS: control, 2.4fold; PXE, 4.8-fold). Serum-dependent induction of PCSK9 expression was also confirmed in siRNA-transfected fibroblasts (Figure 6b), whereas transcript levels of ABCC6silenced cells (grown in 10\% LPDS) were 2.6-fold higher than negative controls. Protein expression of PCSK9 was significantly increased in PXE fibroblasts compared to controls in every cell culture setting (Figure $6 \mathrm{c}:+10 \%$
FCS: 1.7-fold; +10\% LDPS: 1.6-fold; -FCS: 1.4-fold). Protein levels in siRNA treated cells were increased by trend under LDPS and without FCS. However, no significant changes were found between treatments, except for a slight increase in LPDS according to mRNA expression.

PCSK9 plays a pivotal role in lipoprotein regulation promoting LDLR degradation [41]. Measurements displayed increasing mRNA levels of LDLR under lipoprotein deficiency and serum starvation in PXE, control and siRNA-treated fibroblasts (Figure 6e, f). Moreover, gene expression was enhanced in PXE and ABCC6- 

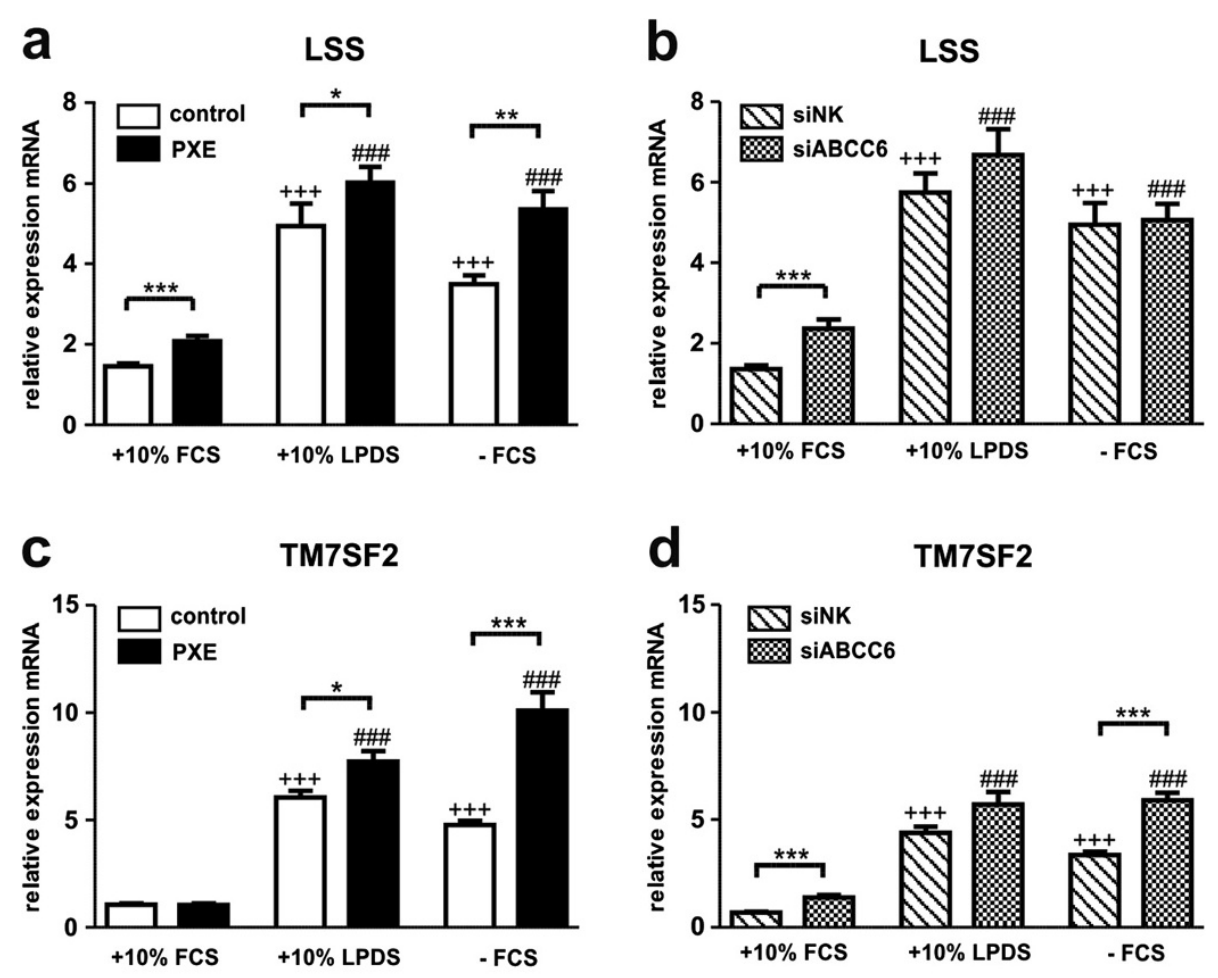

TM7SF2
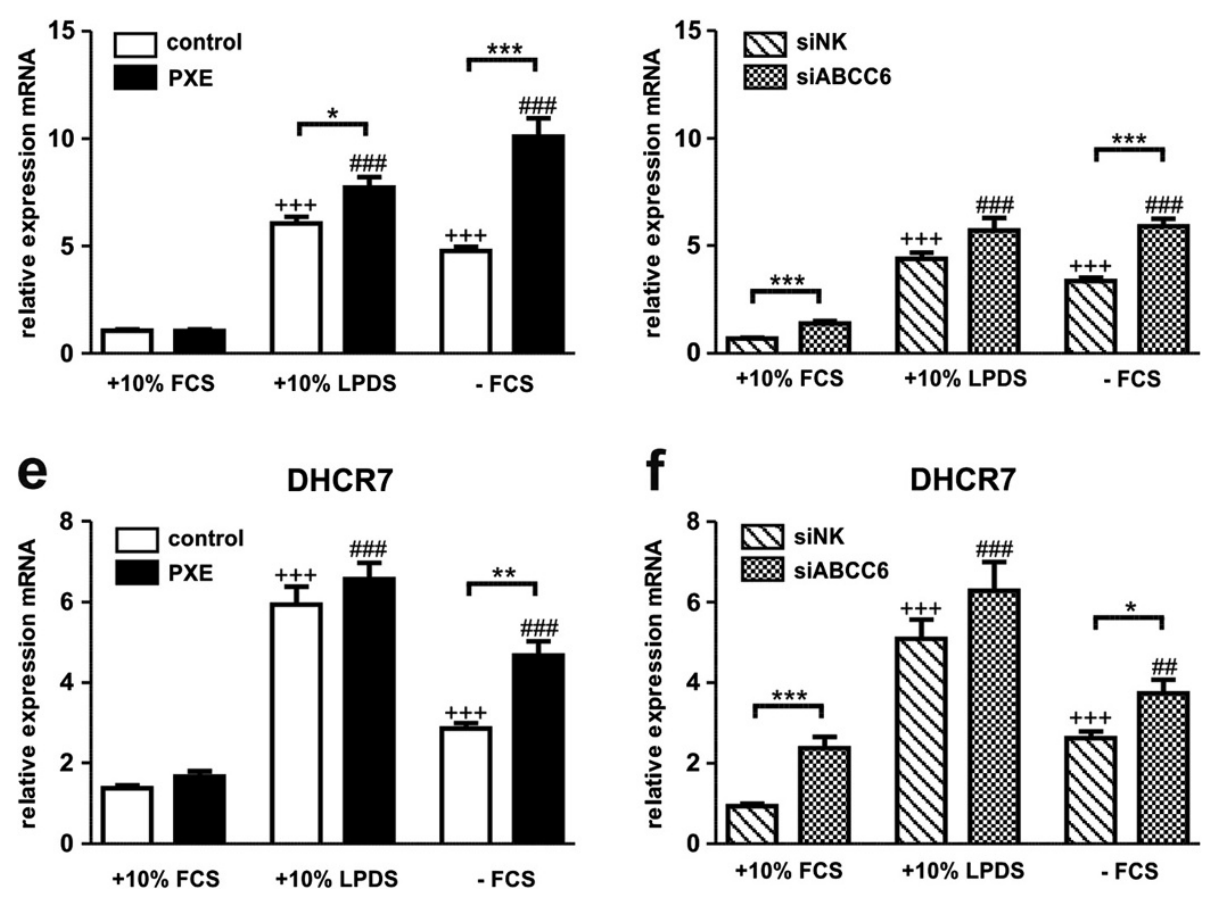

Figure 4 Gene expression analysis of cholesterol biosynthesis II: LSS, TM7SF2 and DHCR7. Quantification of (a, b) Lanosterol synthase (LSS), (c, d) transmembrane 7 superfamily member 2 (TM7SF2) and (e, f) 7-dehydrocholesterol reductase (DHCR7) mRNA expression in human dermal fibroblasts from healthy controls $(n=4$; white), PXE patients $(n=4$; black), scramble siRNA-negative control $($ siNK, $n=4$; white-striped) and ABCC6-specific siRNA-treated cells (siABCC6, $n=4$; black-shaded) grown for $24 \mathrm{~h}$ under different cell culture conditions $(+10 \% \mathrm{FCS},+10 \% \mathrm{LPDS},-\mathrm{FCS})$. Expression levels are normalized to reference gene expressions (ACTB, GAPDH, $32 \mathrm{M}$ ). Data are presented in arbitrary units as means with corresponding standard error. Control: PXE ratio/siABCC6: siNK ratio: ${ }^{* * *} \mathrm{p}<0.0005 ;{ }^{* *} \mathrm{p}<0.005 ;{ }^{*} \mathrm{p}<0.03$; Control 10\% FCS: 10\% LPDS, $-\mathrm{FCS}$ ratio/siNK 10\% FCS: $10 \%$ LPDS, -FCS ratio: +++p < 0.0001; PXE 10\% FCS: 10\% LPDS, -FCS ratio/siABCC6 10\% FCS: 10\% LPDS, -FCS ratio: \#\#\#p <0.0001; \#\#p <0.002.

silenced cells grown in serum-free media compared to controls.

Variations in apolipoprotein gene expression profiles between PXE fibroblasts and healthy controls

Array analysis indicated differences in gene expression levels of APOD, APOE and APOL1 between patients' fibroblasts and controls (see section $\mathrm{RT}^{2}$ Profiler PCR Array). As shown in Figure 7a, PXE fibroblasts exhibited increased APOD expression compared to controls, apparently independently of cell culture conditions.
However, no differences were found between siRNAtransfected cells (Figure 5b), whereas mRNA levels were significantly elevated in serum-free media compared to $10 \%$ FCS (siNK, 5.1-fold, $\mathrm{p}<0.005$; siABCC6, 4.7-fold, $\mathrm{p}<0.05$ ).

Strongly depleted gene expression was observed for APOE in PXE fibroblasts (Table 1) by array analysis. This was confirmed by further qPCR which revealed an overall decrease of 93-94\% in APOE transcript levels in comparison to controls (Figure 7c). Though, no significant alterations were detected between ABCC6-silenced 

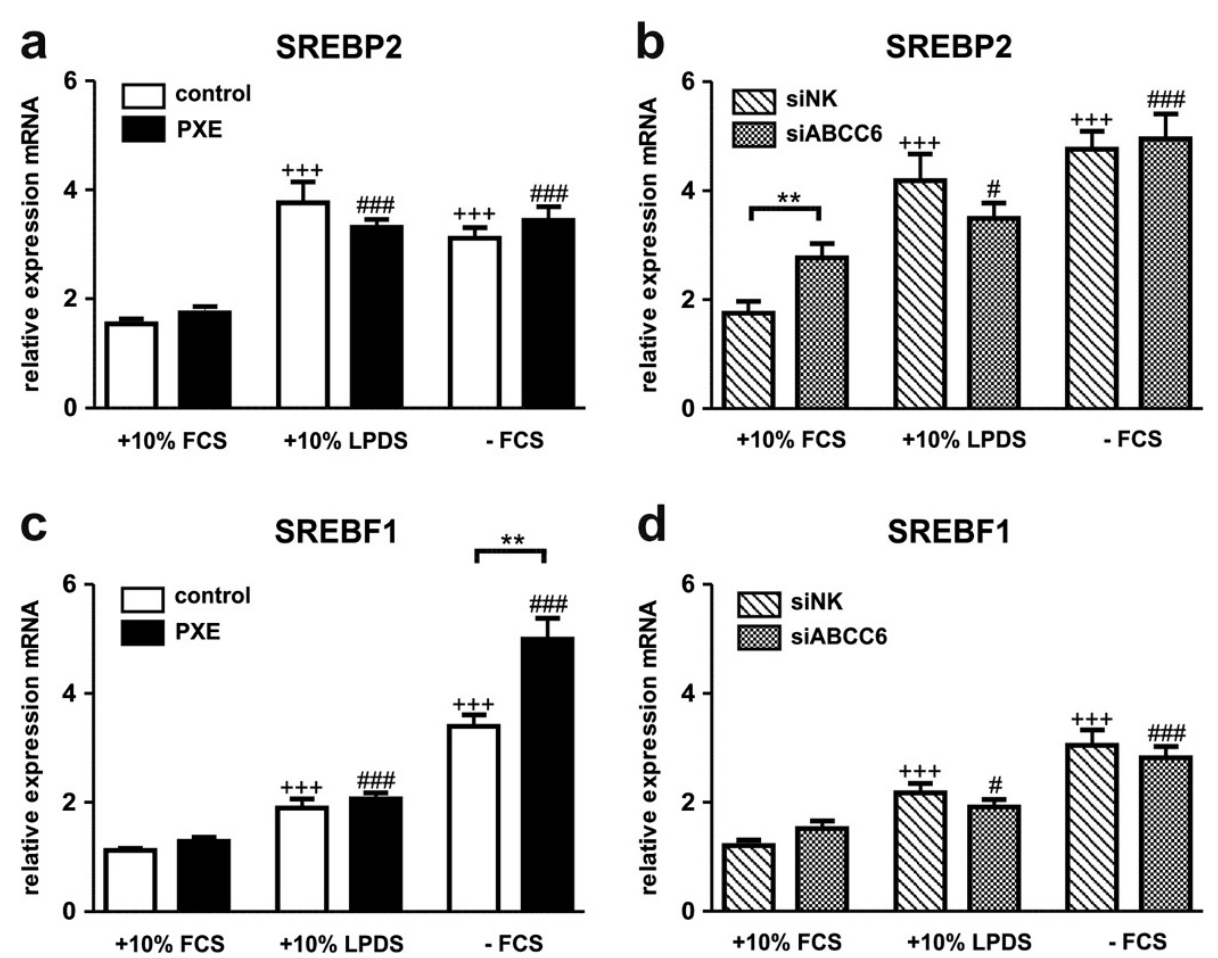

Figure 5 Gene expression analysis of Sterol regulatory element-binding protein 2 (SREBP2) and sterol regulatory element binding factor 1 (SREBF1). Quantification of (a, b) Sterol regulatory element-binding protein 2 (SREBP2) and $(\mathbf{c}$, $\mathbf{d}$ ) sterol regulatory element binding factor 1 (SREBF1) mRNA expression in human dermal fibroblasts from healthy controls ( $n=4$; white), PXE patients $(n=4$; black), scramble siRNA-negative control (siNK, $n=4$; white-striped) and ABCC6-specific siRNA-treated cells (siABCC6, $n=4$; black-shaded) grown for $24 \mathrm{~h}$ under different cell culture conditions ( $+10 \%$ FCS, $+10 \%$ LPDS, $-F C S)$. Expression levels are normalized to reference gene expressions (ACTB, GAPDH, $\beta 2 \mathrm{M})$. Data are presented in arbitrary units as means with corresponding standard error. Control: PXE ratio/siABCC6: siNK ratio: ${ }^{* *} \mathrm{p}<0.006$; Control 10\% FCS: 10\% LPDS, -FCS ratio/siNK 10\% FCS: 10\% LPDS, -FCS ratio: +++p < 0.0002; PXE 10\% FCS: 10\% LPDS, -FCS ratio/siABCC6 10\% FCS: 10\% LPDS, -FCS ratio: \#\#\# < 0.0008; \#p < 0.03 .

fibroblasts and negative controls, except slightly decreased expressions of APOE in 10\% FCS and without serum supplementation (Figure 7d). In general, APOE gene expression was highly induced under serum starvation in control fibroblasts (4.3-fold) and siRNA negative controls (2.5-fold; Figure 7c, d). Measurements of APOE transcript levels were accompanied by genomic sequence analysis of APOE allele variations in patients and control samples (Additional file 4: Table S4). Two PXE patients and controls were found to carry the abundant $\varepsilon 3$ isoform homozygously, whereas one PXE patient carried the $\varepsilon 3 / \varepsilon 2$ alleles in heterozygous state. Two controls were found to bear the heterozygous $\varepsilon 3 / \varepsilon 4$ genotype. Additionally, the $\varepsilon 2$ isoform was detected for PXE patient 1 in homozygous state.

PXE fibroblasts showed increased APOL1 gene expression in serum-free media in comparison to controls (Table 1). These results were confirmed by further RTQPCR measurements, as shown in Figure 7e. APOL1 expression was significantly higher in patients' cells compared to controls in 10\% FCS (1.9-fold) and -FCS (2.2-fold), whereas cultivation in lipoprotein-deficient serum showed just a slight increase. However, no significant alterations were found between siRNA-treated fibroblasts (Figure 7f).

\section{Gene expression of CYP27A1- a marker for cholesterol hydroxylation and bile acid synthesis}

Gene expression of cytochrome P450, family 27, subfamily A, polypeptide 1 (CYP27A1) was significantly induced in cells grown in 10\% LPDS and without serum supplementation (Figure 8a, b). PXE fibroblasts were found to exhibit higher transcript levels under serum starvation in comparison to healthy controls (1.7-fold), whereas expression was slightly decreased in LPDS (20\%; Figure 8a). However, no differences were detected between ABCC6-silenced fibroblasts and controls (Figure 8b).

\section{Targeting $A B C C 2$ and $A B C C 3$ - important members of bile salt transport}

PXE fibroblasts grown in serum-free media showed 2.0fold increase in $\mathrm{ABCC} 2$ gene expression, compared to 

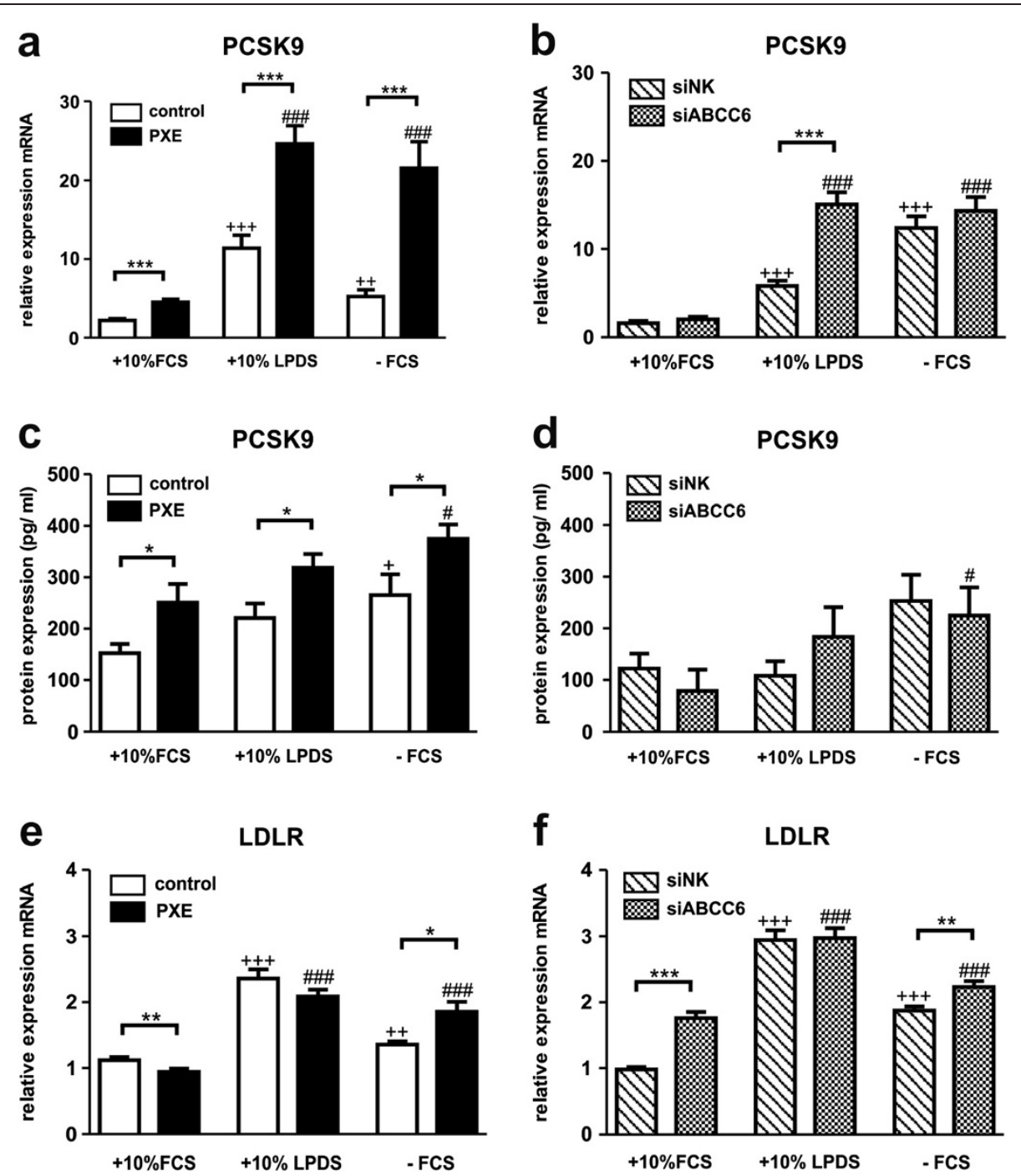

Figure 6 Gene and protein expression analysis of proprotein convertase subtilisin/kexin type 9 (PCSK9) and low density lipoprotein receptor (LDLR). Quantification of $(\mathbf{a}, \mathbf{b})$ mRNA (c, $\mathbf{d})$ PCSK9 protein content $(\mathbf{p g} / \mathrm{ml})$ and $(\mathbf{e}, \mathbf{f})$ LDLR mRNA expression in human dermal fibroblasts from healthy controls $(n=4$; white), PXE patients $(n=4$; black), scramble siRNA-negative control (siNK, $n=4$; white-striped) and ABCC6specific siRNA-treated cells (siABCC6, $n=4$; black-shaded) grown for $24 \mathrm{~h}$ under different cell culture conditions (+10\% FCS, $+10 \%$ LPDS, - FCS). Gene expression levels are normalized to reference gene expressions (ACTB, GAPDH, B2M). Cell lysates for ELISA analysis were pooled from three biological replicates, measured in duplicates. Data are presented in arbitrary units as means with corresponding standard error. Control: PXE ratio/siABCC6: siNK ratio: ${ }^{* * *} p<0.0001$; ${ }^{* *} p<0.003$; ${ }^{*} p<0.05$; Control 10\% FCS: 10\% LPDS, -FCS ratio/siNK 10\% FCS: 10\% LPDS, -FCS ratio: +++p < $0.0001 ;++p<0.002 ;+p<0.02 ;$ PXE 10\% FCS: 10\% LPDS, -FCS ratio/siABCC6 10\% FCS: 10\% LPDS, -FCS ratio: \#\#\#p 0.0001; \#p <0.03.

10\% FCS and control cells (Figure 9a). On the other hand, the expression pattern of control fibroblasts and siRNA-transfected cells was unchanged or moderately depleted between cell culture settings (Figure 9a, b).

Analysis of $\mathrm{ABCC} 3 \mathrm{mRNA}$ expression revealed significant reduction in PXE and ABCC6-silenced cells compared to controls (Figure 9c, d). A 50- 60\% reduction was found in PXE fibroblasts, whereas ABCC6knockdown exhibited 20-35\% depletion. These regulations were found to be independent of cell culture conditions.

\section{Discussion}

In this study, we describe for the first time alterations in cellular cholesterol and lipoprotein metabolism in human dermal fibroblasts from patients with Pseudoxanthoma elasticum. Gene expression analysis of 84 targets involved in cholesterol biosynthesis and lipoprotein assembly indicated dysregulations in response to ABCC6 deficiency. Highly increased or downregulated genes were further examined under different cell culture conditions $(+10 \%$ FCS, $+10 \%$ LPDS, - FCS $)$, inducing HMG CoA 

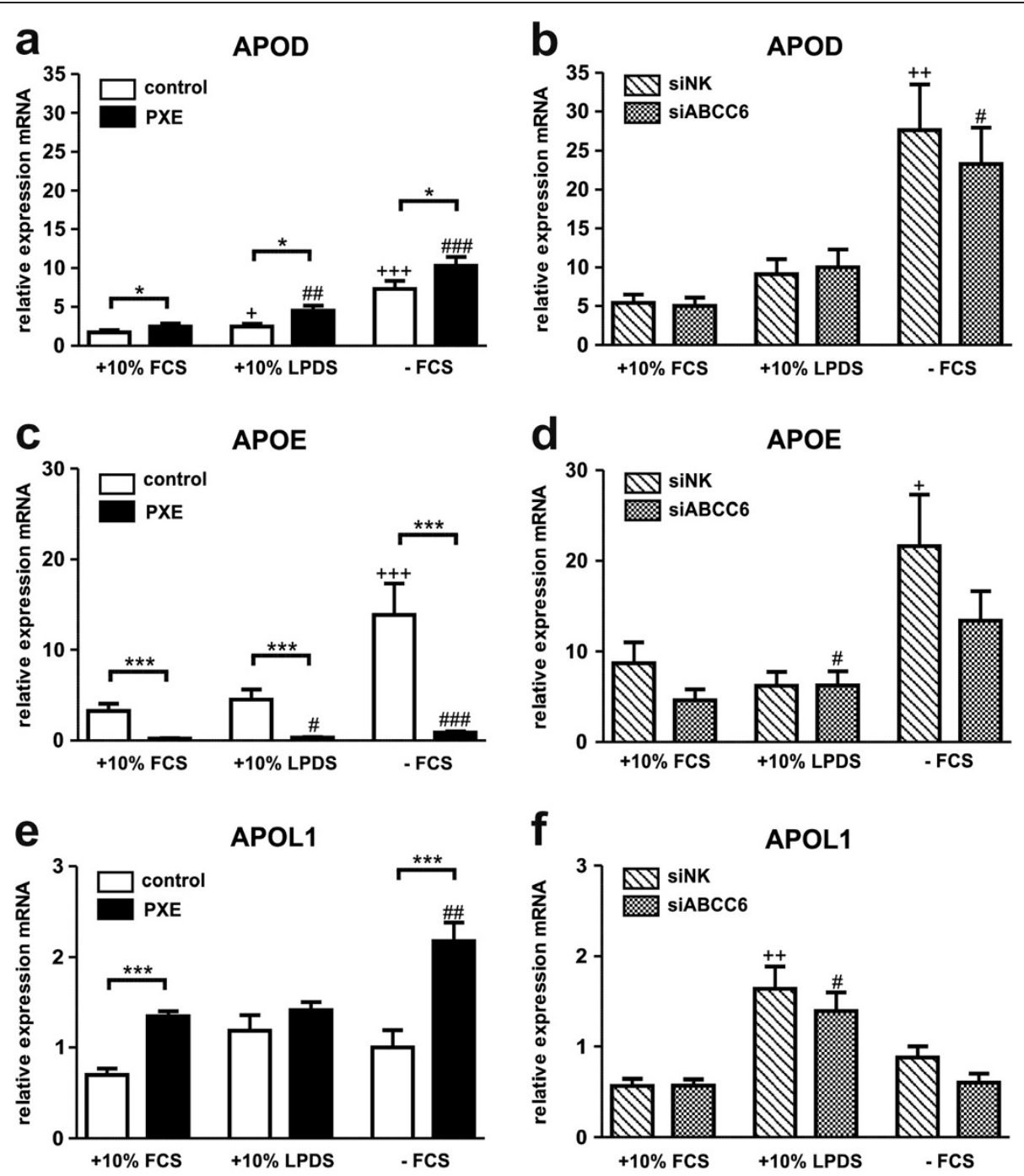

Figure 7 Gene expression analysis of Apolipoproteins: APOD, APOE and APOL1. Quantification of $(\mathbf{a}, \mathbf{b})$ apolipoprotein D (APOD), (c, d) apolipoprotein E (APOE) and (e, f) apolipoprotein L1 (APOL1) mRNA expression in human dermal fibroblasts from healthy controls ( $n=4$; white), PXE patients ( $n=4$; black), scramble siRNA-negative control (siNK, $n=4$; white-striped) and ABCC6-specific siRNA-treated cells (siABCC6, $n=4$; black-shaded) grown for $24 \mathrm{~h}$ under different cell culture conditions ( $+10 \% \mathrm{FCS},+10 \%$ LPDS, $-\mathrm{FCS}$ ). Expression levels are normalized to reference gene expressions (ACTB, GAPDH, $\beta 2 \mathrm{M}$ ). Data are presented in arbitrary units as means with corresponding standard error. Control: PXE ratio/siABCC6: siNK ratio: ${ }^{* *} \mathrm{p}<0.0001 ;{ }^{*} \mathrm{p}<0.03$; Control 10\% FCS: 10\% LPDS, -FCS ratio/siNK 10\% FCS: 10\% LPDS, -FCS ratio: $+++p<0.0004 ;++p<0.003 ;+p<0.04$; PXE 10\% FCS: 10\% LPDS, -FCS ratio/siABCC6 10\% FCS: 10\% LPDS, -FCS ratio: \#\#\#p <0.0001; \#\#p < 0.005; \#p < 0.05.

reductase activity. However, a few results from array analysis could not be confirmed by additional qPCR, pointing towards the need for additional data verification of microarray analysis by secondary methods [42].

Transcript levels of ABCC6 were strongly increased in lipoprotein-deficient serum (LPDS) and under serum-free conditions in control and siRNA treated cells. ABCC6 silencing reached 65- 75\%, whereas mRNA expression levels of ABCC6 were overall diminished in siRNA treatments in comparison to controls without transfection. To what extent this was caused by liposome-based transfection, or enlarged cultivation time $(+24 \mathrm{~h})$ for siRNA treatments is not clear. As shown before, no ABCC6 mRNA could be detected in fibroblasts from PXE patients [18].

The main results of this study are summarized in Figure 10. We used human dermal fibroblasts as a cellular model for ABCC6 deficiency in peripheral cells, in addition to their functional role in extracellular matrix assembly. Previously published data showed that fibroblasts from PXE patients exhibit a characteristic phenotype distinct from healthy controls, affecting $\mathrm{ABC}$ transporter expression [18], calcification processes [43], or extracellular matrix organization [44,45]. ABCC6 is predominately expressed in the liver and kidney and transcript levels in 

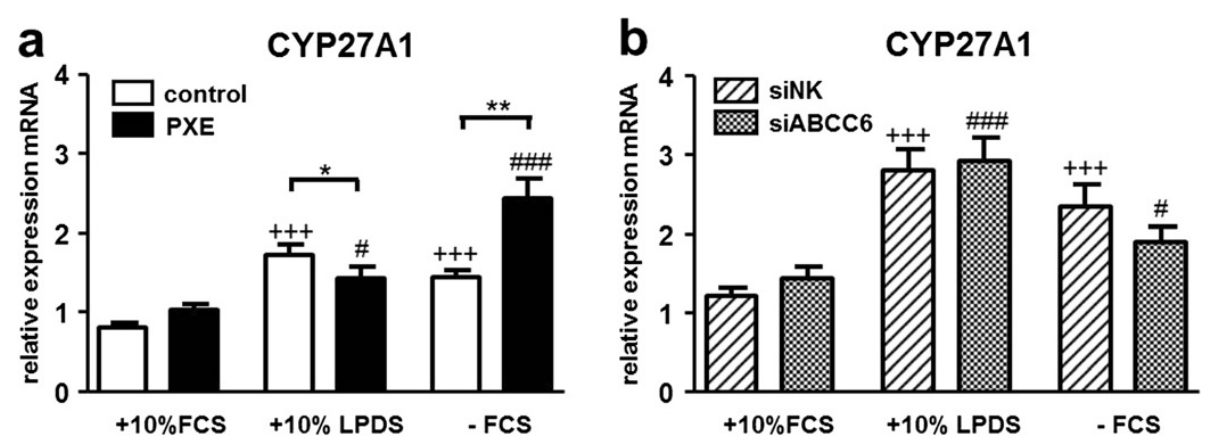

Figure 8 Gene expression analysis of CYP27A1. Quantification of $(\mathbf{a}, \mathbf{b})$ CYP27A1a mRNA expression in human dermal fibroblasts from healthy controls ( $n=4$; white), PXE patients ( $n=4$; black), scramble siRNA-negative control (siNK, $n=4$; white-striped) and ABCC6-specific siRNA-treated cells (siABCC6, $n=4$; black-shaded) grown for $24 \mathrm{~h}$ under different cell culture conditions ( $+10 \% \mathrm{FCS},+10 \%$ LPDS, $-\mathrm{FCS}$ ). Expression levels are normalized to reference gene expressions (ACTB, GAPDH, $\beta 2 \mathrm{M})$. Data are presented in arbitrary units as means with corresponding standard error. Control: PXE ratio/siABCC6: siNK ratio: **p $<0.002$; ${ }^{*} \mathrm{p}<0.05$; Control 10\% FCS: 10\% LPDS, -FCS ratio/siNK 10\% FCS: $10 \%$ LPDS, -FCS ratio: $+++p<0.0002$; PXE 10\% FCS: 10\% LPDS, -FCS ratio/siABCC6 10\% FCS: 10\% LPDS, -FCS ratio: \#\#\#p <0.0001; \#p <0.04.
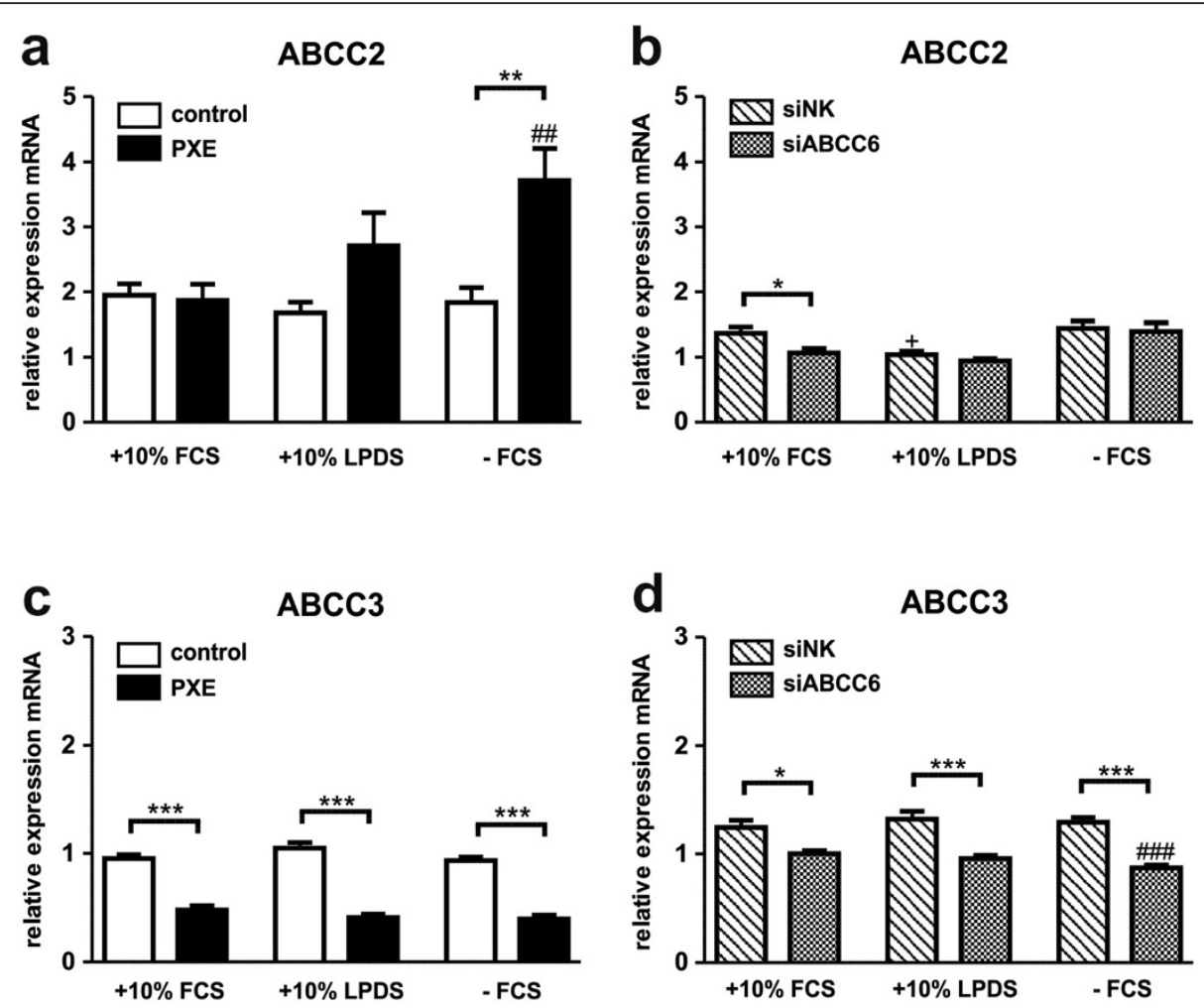

Figure 9 Gene expression analysis of ABCC-Transporters ABCC2 and ABCC3. Quantification of (a, b) ABCC2 and (c, d) ABCC3 mRNA expression in human dermal fibroblasts from healthy controls $(n=4$; white), PXE patients $(n=4$; black), scramble siRNA-negative control (siNK, $\mathrm{n}=4$; white-striped) and ABCC6-specific siRNA-treated cells (siABCC6, $\mathrm{n}=4$; black-shaded) grown for $24 \mathrm{~h}$ under different cell culture conditions $(+10 \% \mathrm{FCS},+10 \%$ LPDS, $-\mathrm{FCS})$. Expression levels are normalized to reference gene expressions (ACTB, GAPDH, $\beta 2 \mathrm{M})$. Data are presented in arbitrary units as means with corresponding standard error. Control: PXE ratio/siABCC6: siNK ratio: ${ }^{* *} p<0.0002 ;{ }^{* *} p<0.005 ;{ }^{*} p<0.02$; Control 10\% FCS: 10\% LPDS, -FCS ratio/siNK 10\% FCS: 10\% LPDS, -FCS ratio: $+p<0.03$; PXE 10\% FCS: 10\% LPDS, -FCS ratio/siABCC6 10\% FCS: 10\% LPDS, -FCS ratio: \#\#\#p < 0.0009; \#\#p < 0.005 . 


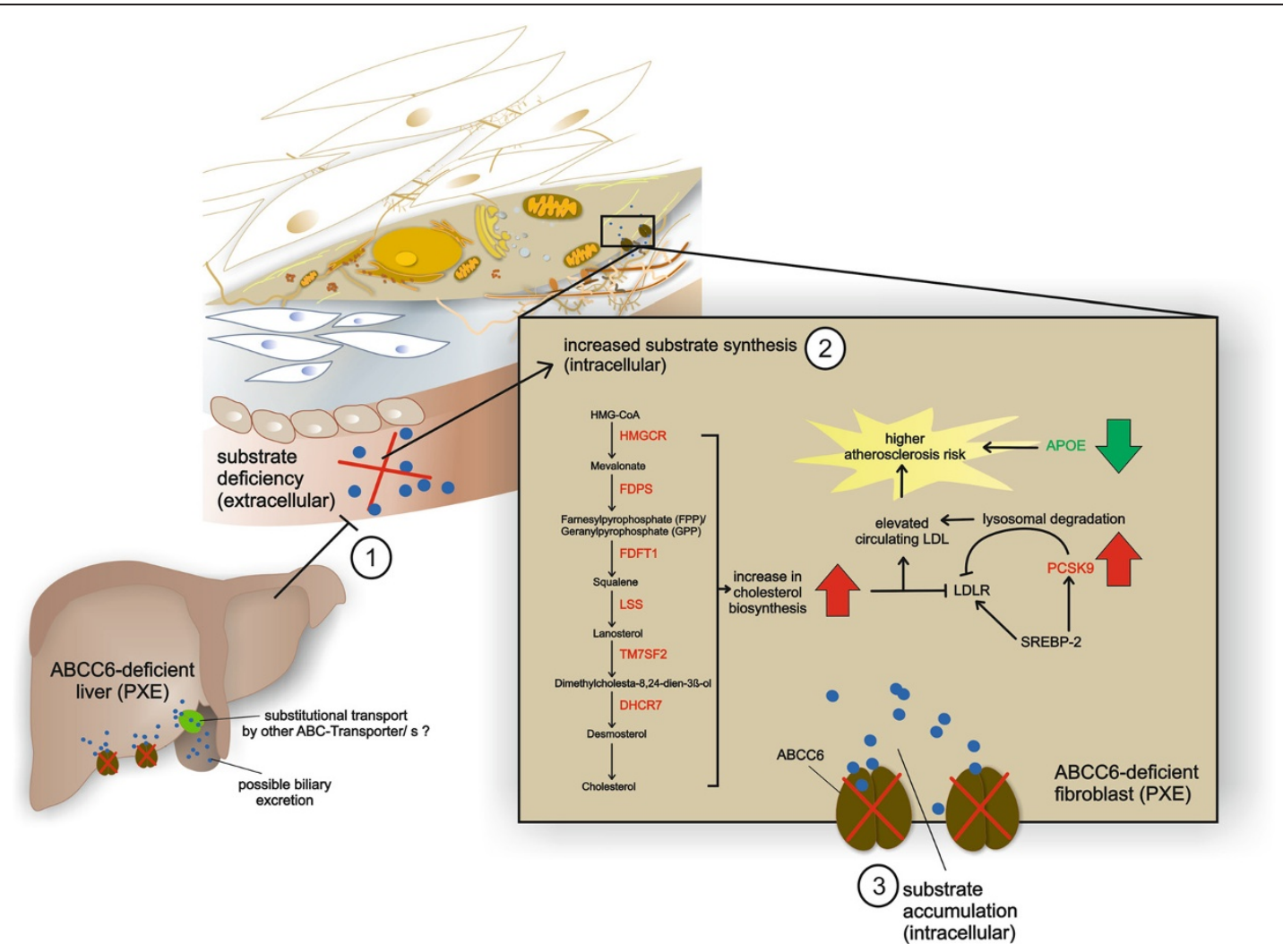

Figure 10 Proposed molecular mechanisms underlying the dysregulations in cholesterol and lipoprotein metabolism in ABCC6-deficient PXE fibroblasts. In case of ABCC6-deficiency in the liver, the potential substrate(s) of ABCC6 is/are missing in the circulation (1). Hepatocytes might possess substitutional routes to prevent possible toxic substrate accumulations (e.g. biliary excretion by other ABC transporter/s). Insufficient substrate supply by the liver then induces substrate biosynthesis in ABCC6-deficient dermal fibroblasts (e.g. cholesterol biosynthesis) (2). Due to a functional loss of ABCC6, newly synthesized metabolites accumulate intracellularly (3) and might provide an additional trigger for dysregulations in cholesterol homeostasis in addition to insufficient hepatic substrate supply.

fibroblasts were shown to be significantly lower [18]. The pathogenesis of PXE is currently explained by the "metabolic hypothesis" and the "peripheral cell hypothesis" $[46,47]$. In case of ABCC6 deficiency in the liver, potential substrate(s) of $\mathrm{ABCC} 6$ is/are missing in the circulation, which leads to the ectopic mineralization processes in peripheral tissues. However, the liver is not affected in PXE patients and hepatocytes might possess substitutional routes to prevent possible toxic substrate accumulations (e.g. biliary excretion by other $\mathrm{ABC}$ transporter/s). Theoretically, mineralization can occur due to substrate deficiency in peripheral tissues, which normally counteracts calcification processes. On the other hand, mineralization can be forced by intracellular substrate biosynthesis in ABCC6-deficient cells (e.g. dermal fibroblasts), which is induced by insufficient substrate supply by the liver and subsequent harmful accumulation affecting intracellular pathways. Recent studies have demonstrated that cholesterol and its precursors are mainly generated in the liver (supplying extrahepatic tissues) $[48,49]$, but can even be newly synthesized by peripheral cells, e.g. by human dermal fibroblasts $[50,51]$.
Many $\mathrm{ABC}$ transporters are involved in lipid homeostasis, including RCT and phospholipid or cholesterol efflux $[3,26]$. Recent studies showed variations in plasma and serum lipoprotein and triglyceride concentrations in PXE patients $[27,29]$. We investigated human dermal fibroblasts from PXE patients and healthy controls under standard cell culture conditions and by inducing cholesterol biosynthesis (HMGCR activity) through lipoprotein deficiency (LPDS) or serum-free (-FCS) cultivation, as shown before [36,50]. Measurement of HMG CoA reductase activity showed for the first time a significant increase in cholesterol biosynthesis rates in PXE fibroblasts in comparison to healthy controls, which was observed under all tested cell culture settings. These data were confirmed by further qPCR measurements of important targets in cholesterol biosynthesis (FDPS, GGPS1, FDFT1, LSS, TM7SF2, DHCR7), which revealed overall increased transcript levels in PXE patients, predominately under serum starvation and using LPDS. Therefore, our data indicate a conceivable role for ABCC6 in human cellular cholesterol and lipoprotein metabolism, observing significant differences between PXE fibroblasts and healthy controls. 
The results of our study provide a first hint, uncovering the molecular mechanisms underlying the positive outcome of statin treatment observed in $\mathrm{Abcc6}^{-/-}$mice [31,52]. Moreover, newly published data including wholegenome sequencing of 89 individuals of polar and brown bears revealed that ABCC6 is one of the important genes which has been under high positive selection in polar bears, enabling to deal with life-long elevated LDL levels that are associated with high risk of heart disease in humans [53].

Most of these results were approved by siRNA knockdown experiments. However, highest ABCC6 mRNA expression under serum starvation could not directly be correlated to the highest HMGCR activity, which was found in $10 \%$ LPDS. Nevertheless, higher cholesterol biosynthesis in PXE could be an important proatherosclerotic factor also affecting calcification progress. The missing correlation of HMG CoA activity and ABCC6 mRNA levels could be explained by further serum factors which may participate in transcription control or act as direct substrate/s for ABCC6. Therefore, cell cultivation in LPDS and without FCS could underlie different regulations, while substrate/s of ABCC6 could be still existent in LPDS.

Gene expression array data indicated strongly increased transcript levels for the proprotein convertase subtilisin/ kexin type 9 (PCSK9) in PXE fibroblasts, which was also confirmed by additional qPCR and ELISA measurements. Gene expression levels of the LDLR were slightly elevated in PXE fibroblasts and ABCC6-silenced cells compared to controls.

Our study is the first linking ABCC6 deficiency to increased PCSK9 mRNA and protein levels. Pisciotta et al. examined a hypercholesterolemic PXE patient, who was compound-heterozygous for two ABCC6 mutations (p.S317R and p.R1141X) and for further mutations in candidate genes causing autosomal co-dominant hypercholesterolemia [54]. A heterozygous LDLR mutation (p.R574H) was found in this patient, whereas no sequence variations were identified in the PCSK9 gene. PCSK9 is mainly expressed in the liver, but was also found in human fibroblasts [55] (similar to the expression pattern of ABCC6) and plays an important role in LDL receptor lysosomal degradation [41]. Modification of serum lipoprotein content, as well as serum withdrawal, induced PCSK9 gene and protein expression in our experiments. PCSK9 was shown to be increased by peroxisome proliferatoractivated receptor gamma (PPAR $\gamma$ ) ligands [56], bisphosphonate administration [57], statin use or by LXR-agonists [58,59]. On the other hand, farnesoid X Receptor (FXR) agonists, 24(S), 25-epoxycholesterol and the lanosterol synthase inhibitor OSCi decreased PCSK9 expression in human hepatocytes and vascular smooth muscle cells, respectively [58,59]. Interestingly, induction of PCSK9 expression by PPARy ligands was supposed to be dependent on extracellular signal regulated kinases 1 and 2 (ERK 1/2) inhibition [56]. The ERK1/2- hepatocyte nuclear factor 4 alpha $(\mathrm{HNF} 4 \alpha)$-axis has been previously described as an important factor for ABCC6 transcription control and might be an additional link to the observed elevated PCSK9 levels in PXE fibroblasts [60]. In addition to increased cholesterol biosynthesis found in PXE fibroblasts, elevated PCSK9 levels could force atherogenesis and cardiovascular risk in PXE patients. Thus, known regulators for PCSK9 (e.g. oxysterols, bile acids) should be investigated as potential substrate/s for $\mathrm{ABCC6}$ in future studies.

Decreased levels of apolipoprotein E (APOE) are an additional risk factor for the development of atherosclerosis. APOE plays an important role in chylomicron and very low density lipoprotein (VLDL) recycling, interacting with LDL receptors in the liver [61]. Single nucleotide variants in APOE were described as determinants for receptor interaction rates and risk factors for atherosclerosis, hypercholesterolemia or Alzheimer disease [62]. We found different APOE isoforms, like heterozygous $\varepsilon 3 / \varepsilon 2$ and homozygous $\varepsilon 2$ alleles in PXE patients and heterozygous $\varepsilon 3 / \varepsilon 4$ in controls, in addition to the abundant homozygous $\varepsilon 3$ isoform. The presence of at least one $\varepsilon 2$ allele was associated with higher APOE levels and a lower risk for CHD, whereas at least one allele of the isoform $\varepsilon 4$ was shown to predict lower APOE levels and a higher potential to develop CHD and Alzheimer disease [62]. One PXE patient was even characterized by a homozygous $\varepsilon 2$ isoform of APOE, which can be a risk factor for type III hyperlipoproteinemia in 5-10\% of $\varepsilon 2$ homozygous carriers [62].

Gene expression data of array analysis displayed a strong reduction in APOE transcript levels in PXE fibroblasts. We confirmed our observations by further qPCR, whereby mRNA expression of APOE exhibited a significant increase in LPDS and under serum-free cell culture conditions, comparable to the ABCC6 expression pattern. Genetic variations in APOE isoforms between examined subjects were considered by an additional analysis of homozygous $\varepsilon 3$ carriers (PXE $1 / 2$ and Ctl 2/3; data not shown). Comparison of APOE transcript levels of these samples revealed as well significantly reduced levels in PXE patients in 10\% FCS (0.25-fold) and under serum starvation (0.15-fold). Hence, mRNA expression seemed to be regulated independently of genetic polymorphisms of APOE in patients and controls, as recently shown in mononuclear cells from normolipidemic and hypercholesterolemic individuals [63]. For ABCC6-silenced cells, only a slight decrease in APOE mRNA (in 10\% FCS and without FCS) was detected in comparison to scrambled siRNA negative controls. However, these differences could be due to residual ABCC6 protein content of 
knock-down fibroblasts or siRNA transfection method carried out with liposomes, which might have a still unknown impact on overall lipoprotein metabolism.

Increased APOE levels in fibroblasts have recently been described under serum starvation [64]. Furthermore, Ishibashi et al. observed increased PCSK9 expression and decreased hepatic LDLR levels in Apoe ${ }^{-/-}$and NiemannPick type $\mathrm{C} 1\left(\mathrm{Npcl}^{-/}\right)$double knock-out mice [65]. These data suggest dependent regulations between APOE and PCSK9, which might also be important for molecular pathomechanisms in PXE. However, in addition to its functional role in lipoprotein metabolism, regulatory properties in the extracellular matrix and intracellular calcium homeostasis were also described for APOE [66]. Measurement of mRNA expression for APOD and APOL1 also showed significantly increased levels in PXE fibroblasts in comparison to controls, mainly under serum-free conditions. Interestingly, APOD expression was described as increasing under oxidative stress as a protective cellular response $[67,68]$, a characteristic cellular hallmark in PXE [69].

In addition to these new observations in cholesterol biosynthesis and lipoprotein metabolism in PXE fibroblasts, we found increased transcript levels of CYP27A1 in PXE fibroblasts under serum starvation. However, mRNA expression data were not confirmed by siRNA-mediated knockdown. CYP27A1 is a member of the cholesterolhydroxylating enzymes (forming 27-hydroxycholesterol/ 27-OH) expressed in most body tissues, whereas circulating $27-\mathrm{OH}$ is further converted into bile acids in the liver [70]. Increasing expression of CYP27A1 could be a cellular response to higher cholesterol biosynthesis rates [71], as shown here for PXE fibroblasts. However, elevated levels of side-chain hydroxylated oxysterols $(27-\mathrm{OH})$ would be expected to inhibit newly synthesized cholesterol reversely, acting as a LXR ligand [70].

Cellular lipoprotein and cholesterol homeostasis is regulated by intra- and extracellular processes, including the sterol regulatory element-binding proteins (SREBPs) as essential members of transcription control [72]. SREBP2 orchestrates the induction of LDLR, PCSK9 and HMGCR in response to sterol depletion [56]. Gene expression analysis of SREBP2 showed a comparable increase under LPDS and serum-free conditions for controls and PXE fibroblasts, as well as for siRNA-transfected cells. Transcript levels of SREBF1 were increased in 10\% LPDS, but were even higher in serum-free media. SREBF1 can be induced by insulin or liver X receptor (LXR) agonists [73,74] and was shown to be significantly elevated in PXE fibroblasts under serum deprivation in comparison to controls.

Induction of $\mathrm{ABCC} 2$ transcription was recently shown in PXE fibroblasts [18]. These $A B C$ transporters are closely related to $\mathrm{ABCC}$ [75]. $\mathrm{ABCC} 2$ was shown to increase significantly under serum deprivation in PXE fibroblasts. Interestingly, reduction in ABCC3 mRNA levels in PXE fibroblasts and ABCC6-silenced cells, seem to be absolutely independent of cholesterol biosynthesis, or lipoprotein supply. Recently, Kobayashi et al. found that gene regulation of $\mathrm{ABCC} 2$ is linked to LXR-SREBP regulatory pathways [76]. These connection should also be investigated for ABCC6, using promotor analysis for the detection of possible transcriptional factor binding sites for SREBPs.

This is the first study which links ABCC6 deficiency to higher cholesterol biosynthetic rates, alterations in LDLRPCSK9 regulation and decreased APOE mRNA expression. All findings are important atherosclerotic risk factors and should be investigated in future studies, exploring the functional role of ABCC6 in the pathogenesis of PXE and related diseases.

\section{Additional files}

Additional file 1: Table S1. Characterization of human derma fibroblasts derived from PXE patients and healthy controls.

Additional file 2: Table S2. Primer sequences used for $q P C R$.

Additional file 3: Table S3. $R T^{2}$ Profiler PCR Array: Lipoprotein signaling and cholesterol metabolism. Regulated gene expression of human dermal fibroblasts of PXE patients and healthy controls (PXE/ controls) and siRNA transfected cells (siABC6/ siNK) cultivated without FCS for $24 \mathrm{~h}$.

Additional file 4: Table S4. APOE genotyping of PXE patients and healthy controls.

\section{Abbreviations}

ABCC6: ATP-binding cassette, sub-family C, member 6; ACTB: Actin, beta; APOD: Apolipoprotein D; APOE: Apolipoprotein E; APOL1: Apolipoprotein L1; ANGPTL3: Angiopoietin-like 3; $\beta 2 \mathrm{M}$ : Beta-2 microglobulin; CEL: Carboxyl ester lipase; CHD: Coronary heart disease; CYP27A1: Cytochrome P450, family 27, subfamily A, polypeptide 1; CYP39A1: Cytochrome P450, family 39, subfamily A, polypeptide 1; CXCL16: Chemokine (C-X-C motif) ligand 16; DHCR7: 7-dehydrocholesterol reductase; ERK 1/2: Extracellular signal regulated kinases 1 and 2; FCS: Fetal calf serum; FDFT1: Squalene synthase; FDPS: Farnesyl diphosphate synthase; FXR: Farnesoid X Receptor; GAPDH: Glyceraldehyde-3-phosphate dehydrogenase; GGPS1: Geranylgeranyl diphosphate synthase 1; HDL: High-density lipoprotein; HDLBP: High density lipoprotein binding protein; HMGCR: 3-hydroxy-3-methylglutaryl-CoA reductase; HNF4a: Hepatocyte nuclear factor 4 alpha; LDL: Low density lipoprotein; LDLR: Low density lipoprotein receptor; LPDS: Lipoproteindeficient serum; LRP1B: Low density lipoprotein receptor-related protein 1B; LSS: Lanosterol synthase; LXR: Liver X receptor; NPC1L1: Niemann-Pick disease, type C1, gene like 1; OLR1: Oxidized low density lipoprotein (lectinlike) receptor 1; PCSK9: Proprotein convertase subtilisin/kexin type 9; PPARY: Peroxisome proliferator-activated receptor gamma;

PXE: Pseudoxanthoma elasticum; RCT: Reverse cholesterol transport; qPCR: Real-Time quantitative PCR; siNK: Small-interfering RNA negative control; siRNA: Small-interfering RNA; SREBF1: Sterol regulatory elementbinding factor 1; SREBP2: Sterol regulatory element-binding protein 2; TM7SF2: Transmembrane 7 superfamily member 2; TRERF1: Transcriptional regulating factor 1; UPLC: Ultra-performance liquid chromatography; VLDL: Very low density lipoprotein.

\section{Competing interests}

The authors declare that they have no competing interests.

\section{Authors' contributions}

PK performed the experiments, data analysis, interpretation and manuscript writing. JK was responsible for mass spectrometry analysis. MDR and IF 
helped with the experimental work. CG, CK and DH contributed to the design of the study, data interpretation and manuscript preparation. All authors read and approved the final manuscript.

\section{Acknowledgements}

This work was funded by the German Research Foundation (DFG, He 5900/2-1). We thank Christoph Lichtenberg and Patricia Janetzki for their excellent technical assistance and Sarah Kirkby for her linguistic advice. We are grateful to all the PXE patients and their relatives and the Selbsthilfegruppe für PXE Erkrankte Deutschlands e. $V$.

\section{Author details}

${ }^{1}$ Herz- und Diabeteszentrum NRW, Institut für Laboratoriums- und Transfusionsmedizin, Universitätsklinik der Ruhr-Universität Bochum, Georgstraße 11, 32545 Bad Oeynhausen, Germany. ${ }^{2}$ MVZ Labor Limbach Nürnberg, Lina-Ammon-Straße 28, 90471 Nürnberg, Germany.

Received: 20 May 2014 Accepted: 17 July 2014

Published: 27 July 2014

\section{References}

1. Ueda $K: A B C$ proteins protect the human body and maintain optimal health. Biosci Biotechnol Biochem 2011, 75:401-409.

2. Uitto J: The gene family of $A B C$ transporters-novel mutations, new phenotypes. Trends Mol Med 2005, 11:341-343.

3. Tarling EJ, Vallim TQ, Edwards PA: Role of $A B C$ transporters in lipid transport and human disease. Trends Endocrinol Metabol 2013, 24:342-350.

4. Vanakker OM, Hosen MJ, De Paepe A: The ABCC6 transporter: what lessons can be learnt from other ATP-binding cassette transporters? Front Genet 2013, 4(203):1-6.

5. Prunier F, Terrien G, Le Corre Y, Apana AL, Bière L, Kauffenstein G, Furber A, Bergen AA, Gorgels TG, Le Saux O, Leftheriotis G, Martin L:

Pseudoxanthoma Elasticum: Cardiac Findings in Patients and Abcc6-Deficient Mouse Model. PLoS One 2013, 8:e68700.

6. Hendig D, Knabbe C, Götting C: New insights into the pathogenesis of pseudoxanthoma elasticum and related soft tissue calcification disorders by identifying genetic interactions and modifiers. Front Genet 2013, 4(114):1-6.

7. Ronchetti I, Boraldi F, Annovi G, Cianciulli P, Quaglino D: Fibroblast involvement in soft connective tissue calcification. Front Genet 2013 4(22):1-16.

8. Maccari F, Volpi N: Structural characterization of the skin glycosaminoglycans in patients with pseudoxanthoma elasticum. Int J Dermatol 2008, 47:1024-1027.

9. Hendig D, Schulz V, Arndt M, Szliska C, Kleesiek K, Götting C: Role of serum fetuin-A, a major inhibitor of systemic calcification, in pseudoxanthoma elasticum. Clin Chem 2006, 52:227-234.

10. Váradi A, Szabó Z, Pomozi V, de Boussac H, Fülöp K, Arányi T: ABCC6 as a target in pseudoxanthoma elasticum. Curr Drug Targets 2011, 12:671.

11. Plomp AS, Toonstra J, Bergen AA, van Dijk MR, de Jong PT: Proposal for updating the pseudoxanthoma elasticum classification system and a review of the clinical findings. Am J Med Genet A 2010, 152:1049-1058.

12. Vermeer BJ, Mateysen AA, van Gent CM, van Sabben RM, Emeis JJ: The lipid composition and localization of free and esterified cholesterol in different types of xanthomas. J Investig Dermatol 1982, 78:305-308

13. Neidner KH, Martinez-Hernandez A: Localized acquired cutaneous pseudoxanthoma elasticum. J Am Acad Dermatol 1979, 1:523-530.

14. Podet EJ, Shaffer DR, Gianturco SH, Bradley WA, Yang CY, Guyton JR: Interaction of low density lipoproteins with human aortic elastin. Arterioscler Thromb Vasc Biol 1991, 11:116-122.

15. Srinivasan $S$, Yost C, Radhakrishnamurthy B, Dalferes E, Berenson G: Lipoprotein-elastin interactions in human aorta fibrous plaque lesions. Atherosclerosis 1981, 38:137-147.

16. Bergen AA, Plomp AS, Hu X, de Jong PT, Gorgels TG: ABCC6 and pseudoxanthoma elasticum. Pflügers Arch Eur J Physiol 2007, 453:685-691.

17. Beck K, Hayashi K, Nishiguchi B, Le Saux O, Hayashi M, Boyd CD: The distribution of Abcc6 in normal mouse tissues suggests multiple functions for this ABC transporter. J Histochem Cytochem 2003, 51:887-902.

18. Hendig D, Langmann T, Kocken S, Zarbock R, Szliska C, Schmitz G, Kleesiek K, Götting C: Gene expression profiling of $A B C$ transporters in dermal fibroblasts of pseudoxanthoma elasticum patients identifies new candidates involved in PXE pathogenesis. Lab Invest 2008, 88:1303-1315. 19. Boraldi F, Quaglino D, Croce M, Garcia Fernandez M, Tiozzo R, Gheduzzi D, Bacchelli B, Pasquali Ronchetti I: Multidrug resistance protein-6 (MRP6) in human dermal fibroblasts. Comparison between cells from normal subjects and from Pseudoxanthoma elasticum patients. Matrix Biol 2003, 22:491-500

20. Gorgels TG, Hu X, Scheffer GL, Van der Wal AC, Toonstra J, de Jong PT, Van Kuppevelt TH, Levelt CN, de Wolf A, Loves WJ, Scheper RJ, Peek R, Bergen AA: Disruption of Abcc6 in the mouse: novel insight in the pathogenesis of pseudoxanthoma elasticum. Hum Mol Genet 2005, 14:1763-1773.

21. Klement JF, Matsuzaki Y, Jiang Q-J, Terlizzi J, Choi HY, Fujimoto N, Li K, Pulkkinen L, Birk DE, Sundberg JP, Uitto J: Targeted ablation of the abcc6 gene results in ectopic mineralization of connective tissues. Mol Cell BiO 2005, 25:8299-8310.

22. Fülöp K, Jiang $Q$, Pomozi V, Szabó PT, Arányi T, Sarkadi B, Borst P, Uitto J, Váradi A: ABCC6 does not transport vitamin K3-glutathione conjugate from the liver: relevance to pathomechanisms of pseudoxanthoma elasticum. Biochem Biophys Res Commun 2011, 415:468-471.

23. Szabó Z, Váradi A, Li Q, Uitto J: ABCC6 does not transport adenosineRelevance to pathomechanism of pseudoxanthoma elasticum. Mol Genet Metab 2011, 104:421

24. Markello TC, Pak LK, St Hilaire C, Dorward H, Ziegler SG, Chen MY, Chaganti K, Nussbaum RL, Boehm M, Gahl WA: Vascular pathology of medial arterial calcifications in NT5E deficiency: Implications for the role of adenosine in pseudoxanthoma elasticum. Mol Genet Metab 2011, 103:44-50.

25. Borst $P$, van de Wetering $K$, Schlingemann R: Does the absence of ABCC6 (multidrug resistance protein 6) in patients with Pseudoxanthoma elasticum prevent the liver from providing sufficient vitamin $\mathrm{K}$ to the periphery? Cell Cycle 2008, 7:1575-1579.

26. Voloshyna I, Reiss $A B$ : The $A B C$ transporters in lipid flux and atherosclerosis. Prog Lipid Res 2011, 50:213-224.

27. Wang J, Near S, Young K, Connelly PW, Hegele RA: ABCC6 gene polymorphism associated with variation in plasma lipoproteins. J Hum Genet 2001, 46:699-705.

28. Peloso GM, Demissie S, Collins D, Mirel DB, Gabriel SB, Cupples LA, Robins SJ, Schaefer EJ, Brousseau ME: Common genetic variation in multiple metabolic pathways influences susceptibility to low HDL-cholesterol and coronary heart disease. J Lipid Res 2010, 51:3524-3532.

29. Schulz V, Hendig D, Henjakovic M, Szliska C, Kleesiek K, Götting C: Mutational analysis of the ABCC6 gene and the proximal ABCC6 gene promoter in German patients with pseudoxanthoma elasticum (PXE). Hum Mutat 2006, 27:831

30. Pohl A, Devaux PF, Herrmann A: Function of prokaryotic and eukaryotic $\mathrm{ABC}$ proteins in lipid transport. Biochim Biophys Acta Mol Cell Biol Lipids 2005, 1733:29-52.

31. Guo H, Li Q, Chou DW, Uitto J: Atorvastatin counteracts aberrant sof tissue mineralization in a mouse model of pseudoxanthoma elasticum (Abcc6-/-). J Mol Med 2013, 91:1-8.

32. Lamon-Fava S: Statins and lipid metabolism: an update. Curr Opin Lipidol 2013, 24:221-226

33. Vaya J: The association between biomarkers in the blood and carotid plaque composition-focusing on oxidized lipids, oxysterols and plaque status. Biochem Pharmacol 2013, 86:15-18.

34. Khaidakov M, Mitra S, Wang X, Ding Z, Bora N, Lyzogubov V, Romeo F, Schichman SA, Mehta JL: Large impact of low concentration oxidized LDL on angiogenic potential of human endothelial cells: a microarray study. PLoS One 2012, 7:e47421.

35. Urban D, Pöss J, Böhm M, Laufs U: Targeting the proprotein convertase subtilisin/kexin type 9 for the treatment of dyslipidemia and atherosclerosis. J Am Coll Cardiol 2013, 62:1401-1408.

36. Gibson K, Hoffmann G, Schwall A, Broock R, Aramaki S, Sweetman L, Nyhan W, Brandt I, Wappner R, Lehnert W: 3-Hydroxy-3-methylglutaryl coenzyme A reductase activity in cultured fibroblasts from patients with mevalonate kinase deficiency: differential response to lipid supplied by fetal bovine serum in tissue culture medium. J Lipid Res 1990, 31:515-521.

37. Faust I, Roch C, Kuhn J, Prante C, Knabbe C, Hendig D: Human xylosyltransferase-l-a new marker for myofibroblast differentiation in skin fibrosis. Biochem Biophys Res Commun 2013, 436:449-454.

38. Kuzaj P, Kuhn J, Faust I, Knabbe C, Hendig D: Measurement of HMG CoA reductase activity in different human cell lines by ultra-performance 
liquid chromatography tandem mass spectrometry. Biochem Biophys Res Commun 2014, 443:641-645.

39. Bustin SA, Benes V, Garson JA, Hellemans J, Huggett J, Kubista M, Mueller R, Nolan T, Pfaffl MW, Shipley GL, Wittwer CT, Schjerling P, Day PJ, Abreu M, Aguado B, Beaulieu JF, Beckers A, Bogaert S, Browne JA, Carrasco-Ramiro F, Ceelen L, Ciborowski K, Cornillie P, Coulon S, Cuypers A, De Brouwer S, De Ceuninck L, De Craene J, De Naeyer H, De Spiegelaere W, et al: The MIQE guidelines: minimum information for publication of quantitative real-time PCR experiments. Clin Chem 2009, 55:611-622.

40. Wenham P, Price W, Blundell G: Apolipoprotein E genotyping by one-stage PCR. Lancet 1991, 337:1158-1159.

41. Levy E, Ouadda ABD, Spahis S, Sane AT, Garofalo C, Grenier É, Emonnot L, Yara S, Couture P, Beaulieu J-F, Ménard D, Seidah NG, Elchebly M: PCSK9 plays a significant role in cholesterol homeostasis and lipid transport in intestinal epithelial cells. Atherosclerosis 2013, 227:297-306.

42. Chuaqui RF, Bonner RF, Best CJ, Gillespie JW, Flaig MJ, Hewitt SM, Phillips JL, Krizman DB, Tangrea MA, Ahram M, Linehan WM, Knezevic V, Emmert-Buck MR: Post-analysis follow-up and validation of microarray experiments. Nat Genet 2002, 32:509-514.

43. Boraldi F, Annovi G, Vermeer C, Schurgers LJ, Trenti T, Tiozzo R, Guerra D, Quaglino D: Matrix gla protein and alkaline phosphatase are differently modulated in human dermal fibroblasts from PXE patients and controls. J Investig Dermatol 2013, 133:946-954.

44. Le Saux O, Bunda S, VanWart CM, Douet V, Got L, Martin L, Hinek A: Serum factors from pseudoxanthoma elasticum patients alter elastic fiber formation in vitro. J Investig Dermatol 2006, 126:1497-1505.

45. Quaglino D Jr, Boraldi F, Barbieri D, Croce A, Tiozzo R, Pasquali Ronchetti I: Abnormal phenotype of in vitro dermal fibroblasts from patients with pseudoxanthoma elasticum (PXE). Biochim Biophys Acta Mol Basis Dis 2000, 1501:51-62.

46. Quaglino D, Boraldi F, Annovi G, Ronchetti I: The multifaceted complexity of genetic diseases: a lesson from pseudoxanthoma elasticum. Adv Stud Genet Disord 2011, 15:289-318.

47. Uitto J, Li Q, Jiang Q: Pseudoxanthoma elasticum: molecular genetics and putative pathomechanisms. J Investig Dermatol 2009, 130:661-670.

48. Zhao C, Dahlman-Wright K: Liver X receptor in cholesterol metabolism. J Endocrinol 2010, 204:233-240.

49. Goedeke L, Fernández-Hernando C: Regulation of cholesterol homeostasis. Cell Mol Life Sci 2012, 69:1-16.

50. Brown MS, Dana SE, Goldstein JL: Regulation of 3-hydroxy-3-methylglutaryl coenzyme A reductase activity in human fibroblasts by lipoproteins. Proc Natl Acad Sci 1973, 70:2162-2166.

51. Brown M, Dana S, Goldstein J: Cholesterol ester formation in cultured human fibroblasts. Stimulation by oxygenated sterols. J Biol Chem 1975, 250:4025-4027.

52. Luft FC: Pseudoxanthoma elasticum and statin prophylaxis. J Mol Med 2013, 91:1-2.

53. Shiping L, Lorenzen ED, Fumagalli $M$, Li B, Harris $K$, Xiong Z, Zhou L, Korneliussen TS, Somel M, Babbitt C, Wray G, Li J, He W, Wang Z, Fu W, Xiang X, Morgan CC, Doherty A, O'Connell MJ, Mclnerney JO, Born EW, Dalen L, Dietz RD, Orlando L, Sonne CS, Zhang G, Nielsen R, Willerslev E, Wang JW: Population Genomics Reveal Recent Speciation and Rapid Evolutionary Adaptation in Polar Bears. Cell 2014, 157:785-794.

54. Pisciotta L, Tarugi P, Borrini C, Bellocchio A, Fresa R, Guerra D, Quaglino D, Ronchetti I, Calandra S, Bertolini S: Pseudoxanthoma elasticum and familial hypercholesterolemia: A deleterious combination of cardiovascular risk factors. Atherosclerosis 2010, 210:173-176.

55. Chan JC, Piper DE, Cao Q, Liu D, King C, Wang W, Tang J, Liu Q, Higbee J, Xia Z, Di Y, Shetterly S, Arimura Z, Salomonis H, Romanow WG, Thibault ST, Zhang R, Cao P, Yang XP, Yu T, Lu M, Retter MW, Kwon G, Henne K, Pan O, Tsai MM, Fuchslocher B, Yang E, Zhou L, Lee KJ, et al: A proprotein convertase subtilisin/kexin type 9 neutralizing antibody reduces serum cholesterol in mice and nonhuman primates. Proc Natl Acad Sci 2009, 106:9820-9825.

56. Duan Y, Chen Y, Hu W, Li X, Yang X, Zhou X, Yin Z, Kong D, Yao Z, Hajjar DP, Liu L, Liu Q, Han J: Peroxisome proliferator-activated receptor gamma activation by ligands and dephosphorylation induces proprotein convertase subtilisin kexin type 9 and low density lipoprotein receptor expression. J Biol Chem 2012, 287:23667-23677.

57. Bedi $M$, Niesen $M$, Lopez D: Inhibition of squalene synthase upregulates PCSK9 expression in rat liver. Arch Biochem Biophys 2008, 470:116-119.
58. Langhi C, Le May C, Kourimate S, Caron S, Staels B, Krempf M, Costet P, Cariou B: Activation of the farnesoid $X$ receptor represses PCSK9 expression in human hepatocytes. FEBS Lett 2008, 582:949-955.

59. Beyea MM, Reaume S, Sawyez CG, Edwards JY, O'Neil C, Hegele RA, Pickering JG, Huff MW: The oxysterol 24 (S), 25-epoxycholesterol attenuates human smooth muscle-derived foam cell formation via reduced low-density lipoprotein uptake and enhanced cholesterol efflux. J Am Heart Assoc 2012, 1:e000810.

60. de Boussac H, Ratajewski M, Sachrajda I, Köblös G, Tordai A, Pulaski L, Buday L, Váradi A, Arányi T: The ERK1/2-hepatocyte nuclear factor 4 alpha axis regulates human $A B C C 6$ gene expression in hepatocytes. I Biol Chem 2010, 285:22800-22808.

61. van Dijk KW, van Vlijmen BJ, van't Hof HB, van der Zee A, Santamarina-Fojo $S$, van Berkel TJ, Havekes LM, Hofker MH: In LDL receptor-deficient mice, catabolism of remnant lipoproteins requires a high level of apoE but is inhibited by excess apoE. J Lipid Res 1999, 40:336-344.

62. Dergunov A: Apolipoprotein E genotype as a most significant predictor of lipid response at lipid-lowering therapy: Mechanistic and clinical studies. Biomed Pharmacother 2011, 65:597-603.

63. Cerda A, Genvigir FD, Willrich MA, Arazi SS, Bernik M, Dorea EL, Bertolami MC, Faludi AA, Hirata MH, Hirata RD: Apolipoprotein E mRNA expression in mononuclear cells from normolipidemic and hypercholesterolemic individuals treated with atorvastatin. Lipids Health Dis 2011, 10:1-11.

64. Quinn C, Kagedal K, Terman A, Stroikin U, Brunk U, Jessup W, Garner B Induction of fibroblast apolipoprotein E expression during apoptosis, starvation-induced growth arrest and mitosis. Biochem J 2004, 378:753-761.

65. Ishibashi M, Masson D, Westerterp M, Wang N, Sayers S, Li R, Welch CL, Tall AR: Reduced VLDL clearance in Apoe-/- Npc1-/- mice is associated with increased Pcsk9 and Idol expression and decreased hepatic LDL-receptor levels. J Lipid Res 2010, 51:2655-2663.

66. Masliah E, Mallory M, Veinbergs I, Miller A, Samuel W: Alterations in apolipoprotein E expression during aging and neurodegeneration. Prog Neurobiol 1996, 50:493-503.

67. Ganfornina MD, Do Carmo S, Lora JM, Torres-Schumann S, Vogel M, Allhorn M, González C, Bastiani MJ, Rassart E, Sanchez D: Apolipoprotein D is involved in the mechanisms regulating protection from oxidative stress. Aging Cell 2008, 7:506-515.

68. Bajo-Grañeras R, Sanchez D, Gutierrez G, González C, Do Carmo S, Rassart E, Ganfornina MD: Apolipoprotein D alters the early transcriptional response to oxidative stress in the adult cerebellum. J Neurochem 2011, 117:949-960

69. Li Q, Jiang Q, Schurgers LJ, Uitto J: Pseudoxanthoma elasticum: Reduced gamma-glutamyl carboxylation of matrix gla protein in a mouse model (Abcc6-/-). Biochem Biophys Res Commun 2007, 364:208-213.

70. Ali Z, Heverin M, Olin M, Acimovic J, Lövgren-Sandblom A, Shafaati M, Båvner A, Meiner V, Leitersdorf E, Björkhem I: On the regulatory role of side-chain hydroxylated oxysterols in the brain. Lessons from CYP27A1 transgenic and cyp27a1-/- mice. J Lipid Res 2013, 54:1033-1043.

71. Hall E, Ren S, Hylemon P, Redford K, Del Castillo A, Gil G, Pandak W: Mitochondrial cholesterol transport: a possible target in the management of hyperlipidemia. Lipids 2005, 40:1237-1244.

72. Xiaoping Z, Fajun Y: Regulation of SREBP-mediated gene expression. Sheng Wu Wu Li Hsueh Bao 2012, 28:287.

73. Xiao X, Song B-L: SREBP: a novel therapeutic target. Acta Biochim Biophys $\sin 2013,45: 2-10$.

74. Meng Z, Yin Y, LV J, Sha M, Lin Y, Gao L, Zhu Y, Sun Y, Han X: Aberrant activation of liver $X$ receptors impairs pancreatic beta cell function through upregulation of sterol regulatory element-binding protein $1 \mathrm{c}$ in mouse islets and rodent cell lines. Diabetologia 2012, 55:1-12.

75. Douet V, Van Wart CM, Heller MB, Reinhard S, Le Saux O: HNF4 alpha and NF-E2 are key transcriptional regulators of the murine Abcc6 gene expression. Biochim Biophys Acta Gene Struct Expr 2006, 1759:426-436

76. Kobayashi M, Gouda K, Chisaki I, Asada K, Ogura J, Takahashi N, Konishi T, Koshida Y, Sasaki S, Yamaguchi H, Iseki K: Regulation of multidrug resistance protein 2 (MRP2, ABCC2) expression by statins: Involvement of SREBP-mediated gene regulation. Int J Pharm 2013, 452:36-41.

doi:10.1186/1476-511X-13-118

Cite this article as: Kuzaj et al.: ABCC6- a new player in cellular cholesterol and lipoprotein metabolism? Lipids in Health and Disease 2014 13:118. 